\title{
The evolution of interfacial transition zone in alkali-activated fly ash-slag concrete
}

Guohao Fang, Mingzhong Zhang*

Department of Civil, Environmental and Geomatic Engineering, University College London, London, WC1E 6BT, UK

\begin{abstract}
This paper investigates the mechanisms of microstructure evolution of interfacial transition zone (ITZ) in alkali-activated fly ash-slag (AAFS) concrete using scanning electron microscope. Results indicate that the formation of original ITZ depends on the so-called "wall effect", leading to a deficit of large grains and a higher effective alkaline activator/precursor ratio compared to paste matrix. The alkaline reaction process is correspondingly accelerated, which promotes the formation of low Ca C-(N)-A-S-H gels and reduces the porosity in the ITZ. Afterwards, the high Ca C-(N)-A$\mathrm{S}-\mathrm{H}$ gels are generated due to the release of more $\mathrm{Ca}$ from slag, resulting in the continuous refinement of pores. The $\mathrm{C}-(\mathrm{N})-\mathrm{A}-\mathrm{S}-\mathrm{H}$ gels with rich $\mathrm{Si}$ and $\mathrm{Al}$ are then produced at $7 \mathrm{~d}$, attributing to the species diffusion from paste matrix to ITZ. Consequently, a compact and dense microstructure is formed in the ITZ at $28 \mathrm{~d}$, which would be beneficial to the long-term performance of concrete.
\end{abstract}

Keywords: Alkali-activated materials (D); Microstructure (B); Pore size distribution (B); Backscattered electron imaging (B); X-ray mapping (B)

\section{Introduction}

The interfacial transition zone (ITZ) between aggregates and paste matrix is typically regarded as one of the most important features affecting the overall performance of concrete [1-3]. It has long been a key area of research in Portland cement (PC) concrete [4-7]. It is generally agreed that the ITZ lies on the so-called "wall effect", where the packing of cement grains would be disrupted through the surface of aggregates [1, 2]. This is the response for the key feature of ITZ which is primarily related to the deficit of large cement grains, leading to a higher local water-to-cement (w/c) ratio in the ITZ than that in the paste matrix [2]. It would accordingly result in the difference in chemical and physical properties between the ITZ and paste matrix, where a higher proportion of pores, calcium hydroxide $(\mathrm{CH})$ crystals and ettringite can be found in the ITZ $[\underline{8}, \underline{9}]$. Therefore, the ITZ is often regarded as the "weak link" in concrete due to its nature. The relatively high porosity presented in the ITZ would provide an easier pathway for the aggressive ions to penetrate into concrete [10], and the higher content of $\mathrm{CH}$ crystals in the ITZ would lower the resistance of concrete to ionic penetration and facilitate the leaching of $\mathrm{CH}[11]$. Additionally, the relationships between ITZ's features and transport properties of concrete have been investigated by several researchers [12-14]. Winslow et al. [12] applied a hard core/soft shell computer model to simulate the percolation of ITZ in mortar and concrete specimens and reported that the probability of ITZ percolation can be decreased by reducing

\footnotetext{
* Corresponding author.

E-mail address: mingzhong.zhang@ucl.ac.uk (M. Zhang)
} 
the ITZ thickness or the porosity in the ITZ. Wong et al. [13] estimated the effects of ITZ and microcracking on the transport properties of cement-based materials after drying. It was found that the net effect of ITZ on overall transport properties is less significant, whereas the effects of total porosity, tortuosity and microcracks on transport properties are much more significant, especially permeability. Furthermore, the effects of different factors on the ITZ's features and transport properties of cement-based materials have also been systematically investigated [15-17]. Scrivener et al. [15] observed that the particle size distribution of cement would determine the ITZ width, while the presence of aggregate may affect the gradients of microstructure in the ITZ. Leemann et al. [17] found that compaction has notable effects on the porosity and width of ITZ, where the ITZ in conventionally vibrated concrete has a higher porosity and width than self-compacting concrete, leading to a higher oxygen permeability and water conductivity. Different types of cement have minor effects on the porosity and width of ITZ in self-compacting concrete, while the cement types have a strong influence on its permeability [16]. Zhang et al. [18] proved that the lightweight aggregates with a porous outer layer would contribute to the formation of a dense ITZ microstructure, as opposed to the porous ITZ formed around the normal-weight aggregates. Based on this finding, Bentz [19], used lightweight aggregates as internal curing agents for mortar, the results of which indicated that the internal curing using lightweight aggregates can help reduce the ITZ percolation and enhance the resistance to the penetration of chloride ions.

However, the ITZ formed in alkali-activated concrete has totally different features compared to that in PC concrete $[\underline{20}, \underline{21}]$. A few studies have discussed the microstructure and properties of ITZ in alkali-activated fly ash (AAF) concrete and alkali-activated slag (AAS) concrete [21-23]. It was found that in AAF concrete there is no apparent weak ITZ near the aggregates due to the formation of sodium aluminosilicate gels (N-A-S-H gels) rather than $\mathrm{CH}$ crystals in this region [22]. The N-AS-H gels are the major binding phase in AAF concrete, which would promote the interparticle bonding and the macroscopic strength in the ITZ. Additionally, the existence of soluble silicates in the initial alkaline solution would also effectively improve the interfacial bonding between aggregates and pastes in AAF concrete [22]. In AAS concrete, it was observed that the ITZ between aggregates and paste matrix is condensed and uniform, which is attributed to the refinement of pore structure as a result of the filling of reaction products $[\underline{21}, \underline{24}]$. This is because this zone is mainly composed of NC-A-S-H or C-A-S-H gels with lower Ca/Si ratio rather than the expansive (Al-free) gels [23]

In recent years, alkali-activated fly ash-slag (AAFS) concrete as a blended alkali-activated concrete system has been attracted increasing attention because of its potential to provide a good synergy between mechanical properties and durability under ambient curing condition, which cannot be achieved by the sole alkali-activated concrete, e.g. AAF and AAS concrete [25-30]. Although the investigations on ITZ in the sole alkali-activated concrete have been made, the existing knowledge 
of ITZ in AAFS concrete is limited to the simple analysis of local morphology [31]. Therefore, it is vital to conduct more comprehensive studies for a better understanding of the microstructure and properties of ITZ in AAFS concrete, particularly the microstructure formation and development of ITZ that have not been explored. It is known that the microstructure of ITZ can be changed over curing time due to the ongoing chemical reaction, which may affect the performance development of AAFS concrete. Hence, it is necessary to monitor the evolution of ITZ's microstructure over time, starting from a very early age. Furthermore, the mechanism behind its microstructure evolution is still unknown. Thus, the lack of consent related to the microstructure of ITZ in AAFS concrete would lead to open issues regarding its engineering applications, as it might provide with a positive or negative influence on the mechanical and transport properties of concrete.

To this end, the main purpose of this research is to conduct a systematic analysis of the microstructure evolution of ITZ in AAFS concrete, providing needed insight into the mechanisms, by which it evolves over time. A series of tests were carried out with the assistance of scanning electron microscope (SEM) equipment along with backscattered electron (BSE) and energy dispersive X-ray spectrometer (EDS) to investigate the microstructural characteristics as a function of curing ages from the very early age $(3 \mathrm{~h})$ to the later curing age $(28 \mathrm{~d})$. Firstly, the interfacial features between aggregates and paste were characterised to identify the ITZ in AAFS concrete. Afterwards, the formation and development of ITZ were studied through the quantitative analysis of physical packing of fly ash and slag grains against aggregates, reaction process, and pore structure evolution. Finally, the mechanisms of ITZ's evolution were discussed in detail based on the experimental results.

\section{Experimental program}

\subsection{Materials}

Low calcium fly ash (FA) and ground granulated blast-furnace slag (GGBS) were used as precursors $(\mathrm{P})$ in this study, the chemical compositions of which are presented in Table 1 . The particle size distribution and the average particle size of FA and GGBS are listed in Table 2. The commonly used alkaline solutions including sodium silicate (SS) solution and sodium hydroxide (SH) solution were used as alkaline activators $(\mathrm{AL})$. The modulus (molar ratio of $\left[\mathrm{SiO}_{2}\right] /\left[\mathrm{Na}_{2} \mathrm{O}\right]$ ) of SS solution was 2.0, while the molarity of SH solution was set as $10 \mathrm{M}$. The $10 \mathrm{M} \mathrm{SH}$ solution was prepared by mixing SH solid powder ( $>98 \%$ purity) with tap water, in which $400 \mathrm{~g}$ SH solid powder was dissolved into tap water to prepare 1 litre SH solution. It is worth mentioning that the SH solution should be prepared $24 \mathrm{~h}$ before specimen preparation to ensure that it is cooled down to room temperature. The modified polycarboxylate-based superplasticizer (SP) was used as the admixture to improve the workability of AAFS as per previous research [32, 33]. It was reported that the workability of AAFS concrete without SP is not acceptable for engineering applications and the addition of SP is necessary to ensure that the AAFS concrete are workable for casting [33]. It should be noted that the addition of SP would 
also decrease the total porosity of AAFS concrete and consequently improve its compressive strength [33], which might have some effects on the evolution of ITZ. However, since this research mainly aims to investigate the features of ITZ in AAFS that should fulfil the requirement for engineering applications in terms of fresh and hardened properties. Thus, SP was used to improve the workability of AAFS. Limestone aggregates with size of 5-10 $\mathrm{mm}$ were chosen as coarse aggregates, while the standard sands with size of 0.08-2.00 mm manufactured according to EN196-1 [34] were used as fine aggregates.

\subsection{Mix proportion}

The mix proportion of AAFS mixture used in this study was determined according to the authors' previous research [29] and the literature [35-37], which can meet the performance criteria in terms of workability, setting time and compressive strength, such as high workability (i.e. achieving a slump value of $90 \mathrm{~mm}$ or over according to Talha Junaid et al.'s research [38]), suitable setting time (i.e. minimum initial setting time of 60 min according to BS EN 197-1:2011 [39]) and high compressive strength (i.e. minimum 28-d compressive strength of $35 \mathrm{MPa}$ according to ACI M318-05 [누]). Here, the unit volume of AAFS concrete was set as $1 \mathrm{~m}^{3}$, in which the total precursor content was kept constant as $400 \mathrm{~kg} / \mathrm{m}^{3}$. Regarding the binding materials, the relevant mixture proportions (by mass) were set as follows: $\mathrm{FA} / \mathrm{GGBS}$ ratio $=3, \mathrm{AL} / \mathrm{P}$ ratio $=0.45, \mathrm{SS} / \mathrm{SH}$ ratio $=2.0$, and $\mathrm{SP} / \mathrm{P}=0.01$. Considering the aggregates, the total volume of aggregates was the residual volume except for the volume of binding materials, which can be calculated based on the mass and specific density of binding materials (see Table 3 ). Here, the fine and coarse aggregates were set as $35 \%$ and $65 \%$ by the volume of total aggregates respectively, in order to achieve an adequate consolidation of concrete [41].The mass of fine and coarse aggregates was then obtained using their specific density. Accordingly, the mixture of AAFS concrete was determined, as shown in Table 4.

\subsection{Sample preparation}

The mixing process of AAFS concrete is described as follows. Firstly, FA, GGBS, fine and coarse aggregates were dry mixed for $2 \mathrm{~min}$. SS, SH and SP were then added into the mixture and mixed for another 3 min. Afterwards, as shown in Fig. 1a, the fresh concrete was prepared and cast into the plastic cylinder moulds with $\Phi 25 \times 100 \mathrm{~mm}$ from the bottom to the top. The moulds were placed on the vibrating machine for around $2 \mathrm{~min}$ and then sealed with the plastic covers. Finally, the samples (with plastic moulds) were placed in the curing room $\left(20 \pm 2{ }^{\circ} \mathrm{C}, 95 \% \mathrm{RH}\right)$ until the testing ages of 3 h, 12 h, 24 h, $3 \mathrm{~d}, 7 \mathrm{~d}$ and $28 \mathrm{~d}$ were achieved. It should be noted that the earliest testing age was set near the final setting time $(\sim 3 \mathrm{~h})$ to make sure it is practical to prepare a polished section.

At each curing age, the small cylinder specimen with $\Phi 25 \times 3 \mathrm{~mm}$ in the centre of the sample was cut using a low-speed diamond saw which is equipped with a wet-cutting system (see Fig. 1b). As shown in Fig. 1c, the top surface of the cylinder specimen was used for the test. It should be ensured 
that the location of the cylinder specimens cut from each sample is the same, since the ITZ's feature can be changed in different locations due to its anisotropic nature. After cutting, two different methods were applied to stop the hydration of testing samples according to their curing age. For the samples in the early few hours after casting $(3 \mathrm{~h})$, the freeze-drying method was used to stop their hydration. The indication is that this method is regarded as an effective method to instantly preserve the composition and microstructure at a specific time [42], which is crucial for the sample at the very early ages. Considering the experimental procedure, the specimens were immersed in the liquid nitrogen $\left(-195^{\circ} \mathrm{C}\right)$ for $5 \mathrm{~min}$ to freeze up, followed by the step that the specimens were transferred to the freeze-dryer system $\left(-10 \pm 1{ }^{\circ} \mathrm{C}\right)$ for 24 -h drying. For the samples at the later curing ages $(12 \mathrm{~h}$, $24 \mathrm{~h}, 3 \mathrm{~d}, 7 \mathrm{~d}$ and $28 \mathrm{~d}$ ), the solvent exchange method was applied to stop the hydration of testing samples. This method is commonly used to remove the free water inside the hardened sample without significant influences on its microstructure [42]. Herein, the isopropanol solution was used as an organic solvent, which is regarded as the best-known solvent to minimize the effects on microstructure and component in cement [42].The samples were stored in the isopropanol solution for $2 \mathrm{~d}$ and then stored in the vacuum drying dish $\left(20 \pm 2^{\circ} \mathrm{C}\right)$ for another $2 \mathrm{~d}$.

Finally, the sample surface should be well-polished in order to provide a smooth and flat surface for the SEM-BSE test. Firstly, the sample was put inside a cylinder plastic mould (with a diameter of $30 \mathrm{~mm}$ ) and impregnated by epoxy solution (mass of epoxy resin: mass of hardening agent = 25: 3). The epoxy used here belongs to the low viscosity epoxy resin (EPO-TEK ${ }^{\circledR} 301-2$, Epoxy Technology Inc., USA). The plastic mould was then put inside the vacuum mosaic to increase the impregnation depth of epoxy and remove the bubbles within the epoxy solution. The vacuum impregnation is essential to fill the pores of the specimen with epoxy solution prior to grinding and polishing, which would stabilize the microstructure and serve to withstand the stresses of grinding and polishing without alteration [43]. When the impregnation was finished, the plastic mould was put inside the vacuum drying dish under ambient condition $\left(20 \pm 2{ }^{\circ} \mathrm{C}\right)$ for the hardening of epoxy. After around 24 $\mathrm{h}$, the sample with epoxy was demould and prepared for grinding and polishing. The automatic pressure polishing machine (BUEHLER, EcoMet ${ }^{\mathrm{TM}} 250$, USA) was used to polish the sample. The rotation speed was set as $30 \mathrm{r} / \mathrm{min}$ while the loading increment was $5 \mathrm{~N}$ to minimize the damage on the sample during grinding and polishing. Herein, the ethyl alcohol was used as a cooling medium and lubricant. The sample was initially ground on the paper disks with a gradation of grits 400 (37 $\mu \mathrm{m}), 800(19 \mu \mathrm{m})$, and $1200(15.3 \mu \mathrm{m})$, respectively. Each grinding time was about $5 \mathrm{~min}$. The sample was then polished on the polishing disks with grits of $2500(5.5 \mu \mathrm{m}), 3000(5 \mu \mathrm{m}), 5000(2.7 \mu \mathrm{m})$ and $7000(1.25 \mu \mathrm{m})$ with a size from large to small. Each polishing step lasted approximately $15 \mathrm{~min}$. After polishing, the samples were stored in a small vacuum bag to avoid potential carbonation (see Fig. 2). 


\subsection{Testing methods}

A field emission SEM equipment (ZEISS, GeminiSEM, Germany) equipped with BSE and EDS was used for microstructure examination. Before testing, the samples were sputter-coated with a layer of carbon under vacuum to increase conductivity. The BSE tests were operated at $10 \mathrm{kV}$ voltages with a working distance of $8.9 \mathrm{~mm}$. Thirty images $(1024 \times 768$ pixels, pixel size of $0.25 \mu \mathrm{m})$ with a magnification of $500 \times$ were captured at a constant brightness $(53.9 \%)$ and contrast $(54.3 \%)$ for reproducibility. To diminish the effects of local variation, a random sampling procedure was adopted, where the images dispersed over different aggregates were randomly obtained. The EDS tests were performed under the "map scanning mode" and the "spot scanning mode", where the electron beam was scanned point by point across the interface between aggregates and paste matrix. The EDS analysis was performed at the beam energy of $15 \mathrm{keV}$ with the probe current of $600 \mathrm{pA}$ and the beam spot size of roughly $450 \mathrm{~nm}$. The working distance of $8.5 \mathrm{~mm}$ and a take-off angle of $35^{\circ}$ were used in this study. The counting rate of 50000 counts per analysis with dead times of about $30 \%$ and the acquisition time of $50 \mathrm{~s}$ were chosen. Here, the EDS map display type is weight percentage, while the EDS spot display type is atomic percentage.

\subsection{Image analysis}

After the BSE images were obtained, a series of image analysis was carried out, which can be divided into four steps, including aggregate boundary delineation, phases identification, strip delineation, and quantitative analysis.

\subsubsection{Aggregate boundary delineation}

A typical BSE image of AAFS concrete after $24 \mathrm{~h}$ of curing is shown in Fig. 3. To specify the interface between aggregates and paste matrix, it is essential to delineate the boundary of aggregates. However, it is not possible to automatically specify the aggregate boundary due to the close grey scale between aggregates and reaction products in the BSE images and the irregular shape of aggregates (see Fig. 3a). Therefore, an artificial method is required to accurately specify the boundary of aggregates. The aggregate boundary delineation mainly includes three steps: (i) detecting the boundary of aggregate, (ii) labelling the edge of aggregate, and (iii) getting rid of aggregate area. In the first step, the original BSEM image was magnified to make sure that the boundary between aggregates and paste matrix can be clearly recognized (see Fig. 3b). The triple magnification was used in this study. As shown in Fig. 3c, the boundary of aggregates can be clearly recognized. Afterwards, the irregular curve was used to label the boundary of aggregates, where the distance between two points was controlled under $3 \mu \mathrm{m}$ to ensure the accuracy of labelling (see Fig. 3d). Next, the labelled aggregate area was cut (see Fig. 3e). Finally, as shown in Fig. 3f, the boundary of aggregate in the whole image was clearly specified. Here, an in-house MATLAB code along with the image processing software called ImageJ was used. 


\subsubsection{Phases identification}

To characterise the interfacial properties of AAFS concrete, it is vital to identify different phases including pores, reaction products and unreacted particles. It should be noted that the term 'pores' used here is regarded as a general term for epoxy-filled voids in the sample, which includes capillary pores, cracks and hollow reaction shells, referring to previous research [44]. Fig. 4 shows a typical greyscale histogram subtracted from a 24-h cured AAFS concrete. The histogram was deconvolved into three Gaussian curves using a statistical analysis software called PeakFit, in which the Gaussian line model was applied. The first Gaussian curve corresponds to the pores, and the second Gaussian curve is attributed to the reaction products while the third Gaussian curve is assigned to the unreacted particles. The threshold value defining the frontier between pores and reaction products was set as the point of intersection between Gauss 1 (pores) and Gauss 2 (reaction products). Similarity, the intersection between Gauss 2 (reaction products) and Gauss 3 (unreacted particles) was defined as the threshold value to specify the boundary between reaction products and unreacted particles. Accordingly, the threshold values of 25 and 132 were determined to distinguish pores, reaction products and unreacted particles, which are shown in Fig. 4. With this method, the threshold values of all testing samples were obtained as listed in Table 5. It is worth mentioning that the determination of threshold values should be adjusted according to each sample, since there is a deviation of this value between different samples. Although all the testing parameters are set as constant values, some deviations between different samples are difficult to be avoided. More details about the phase segmentation for different samples are presented in Appendix A.

\subsubsection{Strip delineation}

In order to characterise the interfacial properties along the distance from the aggregate surface, some successive strips with specified distance were delineated based on the strip delineation method called "concentric expansion" [45]. Therefore, 20 successive strips of 5- $\mu \mathrm{m}$ width were delineated per image and repeated on 30 images for each specimen. A typical example is shown in Fig. 5a. It should be noted that the ITZ width below $5 \mu \mathrm{m}$ cannot be detected.

\subsubsection{Quantitative analysis}

The properties of each strip can then be quantified with the assistance of phase identification mentioned above. Fig. $5 \mathrm{~b}$ shows the volume fractions of different phases, i.e., pores, reaction products and unreacted particles. It should be noted that the segmented pores here are assigned to the porous patches with the greyscale below the threshold defined for pores instead of the single pores. The porous patches mainly consist of interconnected capillary pores, microcracks and hollow shells [46]. This is mainly due to the size limitation of the BSEM images [47]. In this study, the BSEM images with a resolution of $0.25 \mu \mathrm{m}$ cannot provide the direct information of the single pores, because the pore size in AAFS system (typically $<0.1 \mu \mathrm{m}[\underline{33}, \underline{48}]$ ) is smaller than $0.25 \mu \mathrm{m}$. Therefore, in BSEM 
analysis, a cluster of interconnected pores is generally classified as a single pore during the characterisation of pore structures, as it cannot further segment individual pore chambers and throats [49]. Thus, the porosity obtained here is only referred to the pores larger than $0.25 \mu \mathrm{m}$.

In addition, a further statistical analysis of the volume fractions of different phases was performed using one-way analysis of variance (ANOVA) method that is a type of statistical method used to determine whether there are any statistically significant differences between the means of two or more groups of data [50]. Two parameters including $F$-value and $p$-value were obtained to evaluate the statistical significance. The $F$-value represents the ratio of the variation between group means to the variation within the groups, while the $p$-value is the probability value associated with the $F$-value, which is used to evaluate whether the result of $F$-value between different groups is statistically significant. The $p$-value is compared with the significance level to determine whether the observed groups have significant difference [50]. Here, the significance level was set to 0.05 that is commonly used [51]. If the $p$-value is higher than 0.05 , there is no significant difference between the observed groups. Otherwise, if the $p$-value is lower than 0.05 , the observed groups have a significant difference. Furthermore, a $p$-value of lower than 0.01 means there is a strong significant difference between the observed groups. The results of ANOVA tests are shown in Appendix D.

\section{Results and discussion}

\subsection{Characterisation of the interfacial features between aggregate and paste}

The characterisation of interfacial features between aggregates and paste was performed based on the statistical analysis, where multiple regions (at 30 regions in each sample) have been imaged and analysed to ensure that the results obtained can possibly represent the whole specimen. In the analysis, the volume percentage corresponding to each of the identified phases (i.e., pores, unreacted particles and reaction products) was compiled for the strip (with 20 successive 5 - $\mu \mathrm{m}$ strips). The mean values of percentage volume calculated from 30 different locations were used to characterise the variation of phases with distance from the aggregate surface. Fig. 6 shows the mean values of volume fraction of different phases against distance from the aggregate surface at different curing ages. As shown in Fig. 6a, the microstructural gradients between the region close to the surface of aggregate and the region far away can be observed at $3 \mathrm{~h}$, which are less distinct than those in the case of PC system [2]. At $12 \mathrm{~h}$, the similar microstructural gradients are observed in comparison with $3 \mathrm{~h}$. Nevertheless, the content of reaction products at $12 \mathrm{~h}$ is increased dramatically regardless of the distance from aggregate. This can be attributed to the significant reaction process taken place at this very early age, and consequently the volume fraction of pores is decreased dramatically (see Fig. 6b). During the curing ages from $24 \mathrm{~h}$ to $7 \mathrm{~d}$, the content of reaction products is increased slightly regardless of the distance from aggregate, while the content of unreacted particles and pores is decreased slightly (see Fig. 6c to 6e). Similarly, the less distinct microstructural gradients are also identified during these 
curing ages. However, at $28 \mathrm{~d}$, the gradients of reaction products and unreacted particles become conspicuous (see Fig. 6f). The content of reaction products close to the surface of aggregate is higher than the region far away, while the relative low content of unreacted particles can be found in the region close to the aggregate surface. Simultaneously, the content of reaction products is much higher than that at $7 \mathrm{~d}$, while the content of unreacted particles is obviously lower than that at $7 \mathrm{~d}$.

In addition, it is desirable to statistically evaluate the degree of lateral variation for successive narrow strips at a fixed distance from aggregate surface. The lateral variation is normally expressed in terms of standard deviation or the coefficient of variation, which helps to better understand the statistical analysis of mean values [52]. The coefficient of variation was used in this study. Fig. 7 shows the coefficient of variation for the mean volume fraction of different phases against distance from aggregate surface at different curing ages. It can be observed that the coefficient of variation for unreacted particles and reaction products ranges approximately from $10 \%$ to $30 \%$, indicating a relatively low degree of variability from different locations taken at the same distance from aggregate. With this acceptable variation between individual locations, a mean value does adequately describe the situation at the fixed distance from aggregate. Meanwhile, the change in volume fractions of unreacted particles and reaction products corresponds to the key feature of ITZ, as demonstrated in PC system [2] and AAM system [23]. Therefore, the mean values of unreacted particles and reaction products content are used to identify the region of ITZ in this study. In addition, the coefficient of variation for pores ranges widely from $20 \%$ to $100 \%$, implying a large degree of non-uniformity in terms of pore content. This is due to their relatively low concentration and the complicated components including capillary pores, cracks and reaction hollow shells, which would induce great uncertainty between different locations even at the same distance from aggregate. Thus, the change in mean value of pores is superimposed on a complex pattern of irregular variations, which is a normal and inescapable characteristic in the microstructure of cementitious materials [52].

Furthermore, a detailed statistical analysis of the mean values is also crucial to investigate the variation of composition with distance from the aggregate. According to the lateral variation analysis mentioned above, the mean values of unreacted particles and reaction products content were used to define the boundary between ITZ and paste matrix. In order to statistically characterise the variation of composition (i.e. difference of the adjacent data), the coefficients of difference for unreacted particles $\left(D_{u}\right)$ and reaction products $\left(D_{r}\right)$ were introduced as:

$\mathrm{D}_{\mathrm{u}}=\frac{\left|\mathrm{U}_{\mathrm{i}}-\mathrm{U}_{0}\right|}{\mathrm{U}_{0}} \times 100 \%$

$\mathrm{D}_{\mathrm{r}}=\frac{\left|\mathrm{R}_{\mathrm{i}}-\mathrm{R}_{0}\right|}{\mathrm{R}_{0}} \times 100 \%$

where $\mathrm{U}_{0}$ is the volume fraction of unreacted particles in the first strip ( $5 \mu \mathrm{m}$ far from aggregate surface), $U_{i}$ is the volume fraction of unreacted particles in the $i^{\text {th }}$ strip (up to 20 strips with $5 \mu \mathrm{m}$ ), $\mathrm{R}_{0}$ 
is the volume fraction of reaction products in the first strip, and $\mathrm{R}_{\mathrm{i}}$ is the volume fraction of reaction products in the $\mathrm{i}^{\text {th }}$ strip.

Fig. 8 shows the coefficients of difference for unreacted particles and reaction products against distance from aggregate surface at different curing ages. At $3 \mathrm{~h}$, the coefficients of difference for unreacted particles and reaction products are increased steadily from $0 \%$ to $23 \%$ and from $0 \%$ to $41 \%$ respectively with increasing distance from $0 \mu \mathrm{m}$ to $45 \mu \mathrm{m}$, and then fluctuate at around $20 \%$ and $35 \%$ respectively between the distance of $45 \mu \mathrm{m}$ and $95 \mu \mathrm{m}$ (see Fig. 8a). This might suggest that the microstructure close to the aggregate surface is different compared to the region far away. This microstructurally distinct region that is different from the paste matrix can be regarded as the ITZ. As the curing age increases to $12 \mathrm{~h}$, the boundary between unreacted particles and reaction products becomes fuzzy, which is found to be at $40 \mu \mathrm{m}$ from the aggregate surface (see Fig. 8b). Similar phenomena can be observed for the curing ages between $24 \mathrm{~h}$ and $7 \mathrm{~d}$ (see Fig. $8 \mathrm{c}$ to $8 \mathrm{e}$ ), where the boundaries are defined at $50 \mu \mathrm{m}, 40 \mu \mathrm{m}$ and $40 \mu \mathrm{m}$, respectively. However, the boundary becomes obvious again at $28 \mathrm{~d}$ (see Fig. 8f), where the coefficients of different for unreacted particles and reaction products are increased dramatically within the distance between $0 \mu \mathrm{m}$ and $45 \mu \mathrm{m}$ and become relatively stable at $45 \mu \mathrm{m}$ from the aggregate surface.

Microcracking induced by shrinkage is another key interfacial feature between aggregates and paste, which would initiate and propagate preferentially in the ITZ. As seen in the BSEM images in Fig. 9, the microcracks existing in ITZ can be divided into two types, including bond cracks and matrix cracks [13]. The bond cracks appear at the interface between aggregates and paste, while the matrix cracks exist across from aggregate surface to paste matrix. As shown in Fig. 9a, a clear bond crack exists near the interface between aggregate and paste at $3 \mathrm{~h}$. At $12 \mathrm{~h}$, although the interfacial debonding area can be observed, the paste starts to adhere closely to the aggregate at this stage (see Fig. 9b). With the further curing at $24 \mathrm{~h}$, the bond cracks become finer than that at $12 \mathrm{~h}$, while some matrix cracks initiate in the interphase region (see Fig. 9c). As shown in Fig. 9d, a tight bonding between aggregate and paste can be clearly observed at $3 \mathrm{~d}$, where the bond cracks almost disappear. At $7 \mathrm{~d}$, both bond cracks and matrix cracks are difficult to be identified (see Fig. 9e). Finally, the tight bonding between aggregate and paste can also be observed at $28 \mathrm{~d}$, whereas the matrix cracks reappear and propagate from aggregate surface across the paste matrix (see Fig. 9f).

\subsection{Formation and development of ITZ}

In the aforementioned literature, the original ITZ is found to be highly dependent on the packing of raw particles, e.g. cement, FA and GGBS, against the flat surface of aggregates [2]. This phenomenon is called "wall effect", which is responsible for the feature of ITZ, since it would directly affect the grading of unreacted particles, the reaction process and thus the microstructure revolution (especially pore structure). Accordingly, the formation and development of ITZ are discussed from 
three points of view, including physical packing of unreacted particles, reaction process and pore structure evolution.

\subsubsection{Physical packing of fly ash and slag grains in the ITZ}

Fig. 10 presents the grain distribution of FA and GGBS near the surface of aggregate. It can be seen from Fig. 10a that the small particles play a dominant role in the region close to the surface of aggregate, while the large particles can be found further out of the aggregate surface. This phenomenon can be attributed to the obvious difference in size between precursors (FA and GGBS) grains and aggregates. Normally, the size of FA and GGBS is in the range between $0.1 \mu \mathrm{m}$ and 100 $\mu \mathrm{m}$, while the size of aggregate is several orders of magnitude larger than that of fly ash and slag. Thus, each aggregate exists like a mini "wall" in concrete. During the mixing process, the packing of grains through the surface of aggregate would be disrupted, leading to the so-called "wall effect" [2] . Accordingly, the zone with a deficit of large grains that cannot physically pack adjacent to the aggregate is generated, which is the origin of ITZ (see Fig. 10b). The particle size distribution of precursors in ITZ and paste matrix was calculated and shown in Fig. 10c. It can be observed that the diameter of grains in ITZ is much smaller than that in paste matrix. The particle size of precursors in ITZ ranges from $0.5 \mu \mathrm{m}$ to $11.5 \mu \mathrm{m}$, while that in paste matrix covers a larger range between $2.5 \mu \mathrm{m}$ and $62.5 \mu \mathrm{m}$. Nevertheless, it should be mentioned that the particle size distribution would be slightly different due to the random packing of grains even in the same sample (see Appendix B).

In addition, the physical packing of precursors would lead to a deficit of large particles that cannot physically pack close to the aggregate, and consequently results in a relatively low content of precursors in the ITZ. Such features would bring a higher effective alkaline activator/precursor ratio in the ITZ than that in the paste matrix, and eventually induce the differences in physical and chemical properties. As seen in Fig. 11, the mean content of unreacted particles in the ITZ is $51.88 \%$ which is lower than that in the paste matrix (i.e. $53.75 \%$ ) at $3 \mathrm{~h}$. The statistical analysis also indicates a strong significant difference $(p$-value $<0.01)$ between the content of unreacted particles in the ITZ and that in the paste matrix at this curing age (see Table A-1 in Appendix D). As the curing age increases from $3 \mathrm{~h}$ to $7 \mathrm{~d}$, the contents of unreacted particles in the ITZ and paste matrix are decreased slightly due to the alkaline reaction, followed by a dramatic drop at $28 \mathrm{~d}$, where the contents of unreacted particles in the ITZ and paste matrix are decreased to $32.30 \%$ and $36.21 \%$, respectively.

\subsubsection{Reaction process in the ITZ}

The origin of ITZ lies in the "wall effect" of packing of precursors against the aggregate surface, but its microstructure is also associated with the chemical reactions occurred in this region. Fig. 12 shows the volume fraction of reaction products in the ITZ and paste matrix at different curing ages. At the beginning $(3 \mathrm{~h})$, the mean value of volume fraction of reaction products in the ITZ $(37.5 \%)$ is slightly higher than that in the paste matrix (36\%). With the increase of curing age from $3 \mathrm{~h}$ to $12 \mathrm{~h}$, 
the contents of reaction products in the ITZ and paste matrix are increased significantly from $37.5 \%$ to $46 \%$ and from $36 \%$ to $45.5 \%$, respectively. As the reaction continues from $12 \mathrm{~h}$ to $7 \mathrm{~d}$, the contents of reaction products in the ITZ and paste matrix become stable, with a slight increase from $46 \%$ to $48 \%$ and from $45.5 \%$ to $49 \%$, respectively. However, as the curing age changes from $7 \mathrm{~d}$ to $28 \mathrm{~d}$, the volume fractions of reaction products in the ITZ and paste matrix are increased dramatically again from $48 \%$ to $66 \%$ and from $49 \%$ to $62 \%$, respectively. There are more reaction products in the ITZ than in the paste matrix at this stage. Accordingly, the difference of reaction products content in the ITZ and paste matrix becomes obvious at $28 \mathrm{~d}$, with a $p$-value $<0.01$ (see Table A-2 in Appendix D). These results are mainly ascribed to the different reaction process happened in the ITZ and paste matrix, which is discussed in detail below.

Fig. 13 presents the local elemental maps of key elements ( $\mathrm{Na}, \mathrm{Ca}, \mathrm{Si}$ and $\mathrm{Al}$ ) near the interface between aggregates and paste at different curing ages. In the element maps of $\mathrm{Na}$, the distinction between the region close to the aggregate and the region far away from the aggregate is not obvious at all curing ages. This is confirmed by the EDS spot analysis shown in Fig. 14a, where the difference in the mean value of Na percentage between ITZ and paste matrix is smaller than $1 \%$ for all the AAFS samples. The ANOVA test results also suggest that there is no significant difference of $\mathrm{Na}$ content in the ITZ and paste matrix (see Table A-3 in Appendix D). The uniform distribution of Na implies that the content of $\mathrm{Na}$ within the reaction products in the ITZ and paste matrix is similar regardless of curing age.

In the element maps of $\mathrm{Ca}$, the homogeneous intensity can be observed in the interface between aggregate and paste matrix at all curing ages, while the overall intensity of Ca seems to increase with increasing curing ages. These are consistent with the statistical analysis of the Ca percentages in the ITZ and paste matrix (Fig. 14b). The difference in the Ca percentage ranges from $0.13 \%$ to $1.52 \%$, which suggests that the gradient of Ca between ITZ and paste matrix is not obvious. The $p$-values are found to be higher than 0.05 , indicating there is no significant difference (see Table A-4 in Appendix D). This can be attributed to the relatively low content of $\mathrm{Ca}$ in the unreacted particles, where $\mathrm{CaO}$ only occupies $9.7 \%$ of total binding materials according to the chemical composition of $\mathrm{CaO}$ in $\mathrm{FA}$ and GGBS.

In the element maps of $\mathrm{Si}$, the intensity of $\mathrm{Si}$ in the region close to the aggregate is lower than that in the region further out at $3 \mathrm{~h}$. As the reaction proceeds, the difference between these two regions becomes less especially at later curing ages. It can be observed from the EDS spot analysis in Fig. $14 \mathrm{c}$, in which the mean value of Si content in the ITZ is obviously lower than that in paste matrix at 3 -h curing. A significant difference $(p$-value $<0.05)$ of the Si content in the ITZ and paste matrix at this curing age can also be found in the ANOVA test (see Table A-5 in Appendix D). This is consistent with the finding of less fly ash and slag close to the interface of aggregate (see Fig. 11). As the curing 
age increases from $3 \mathrm{~h}$ to $12 \mathrm{~h}$, the content of Si in the ITZ increases significantly from $6.5 \%$ to $8.43 \%$, whereas the content of $\mathrm{Si}$ in the paste matrix only slightly increases from $11.25 \%$ to $11.5 \%$. This indicates that the reaction process in the ITZ is faster than that in the paste matrix because of the higher content of AL/P ratio in this zone, as confirmed by the relatively low content of unreacted particles in the ITZ (Fig. 11). In addition, the difference in the size of gains would also affect the reaction process in the ITZ, where the particle size in the ITZ is smaller than that in the paste matrix due to the "wall effect" (Fig. 10). The smaller particles would be reacted quickly and completely, while the larger particles would be reacted relatively slowly due to the existence of a core of unreacted grains. As a result, the increasing rate of the mobile ions such as Si in the ITZ is higher than that in the paste matrix, and thus the reaction process is fast in this zone. With the increase of curing age from $12 \mathrm{~h}$ to $24 \mathrm{~h}$, the content of Si in the ITZ increases from $8.43 \%$ to $10.77 \%$, while that in the paste matrix only increases slightly from $11.5 \%$ to $11.75 \%$. For the curing ages between $3 \mathrm{~d}$ and $7 \mathrm{~d}$, the percentage of Si in both ITZ and paste matrix becomes stable. However, at $28 \mathrm{~d}$, the content of Si is increased dramatically again, where the Si percentages in ITZ and paste matrix are increased from $10.5 \%$ to $18 \%$ and from $10 \%$ to $16.5 \%$, respectively. The Si content in the ITZ is higher than that in paste matrix in this stage, suggesting that the reaction products formed in the ITZ at $28 \mathrm{~d}$ are rich with Si than the rest of paste, which is consistent with the development of reaction products shown in Fig. 12. Given that the quantity of initial particle of FA and GGBS in the ITZ is lower than that in the paste matrix, some of the mobile ions might come from the dissolution of FA and GGBS outside the ITZ due to the concentration gradient developed with the progress of chemical reactions.

In the element maps of Al, a relatively low intensity adjacent to the surface of aggregate is found at $3 \mathrm{~h}$. As can be seen in Fig. 14d that the mean value of Al content in the ITZ is obviously lower than that in paste matrix at this age. This is further confirmed by the ANOVA test results given in Table A6 that the Al content in the ITZ and paste matrix has a strong significant difference ( $p$-value $<0.01)$. As the curing age increases, the homogeneous intensity of Al can be observed regardless of the distance from aggregate. The percentage of Al in the ITZ is increased dramatically during the curing age from $3 \mathrm{~h}$ to $12 \mathrm{~h}$, while in paste matrix it is changed slightly in this period (see Fig. 14d). After that, it is increased steadily with the increase of curing age regardless of ITZ and paste matrix because of the ongoing reaction in AAFS paste (from $12 \mathrm{~h}$ to $3 \mathrm{~d}$ ). During these curing ages, there is no significant difference ( $p$-value $>0.05$ ) of the Al content in the ITZ and paste matrix (see Table A-6 in Appendix D). Besides, the content of Al in the ITZ is lower than that in paste matrix at early $7 \mathrm{~d}$ but it is higher than that in paste matrix at $28 \mathrm{~d}$, which is consistent with the development of reaction products shown in Fig. 12 and the release process of Si (see Fig. 14c). The $p$-value is found to be lower than 0.05 , further suggesting that there is a significant difference of the Al content in the ITZ and paste matrix at $28 \mathrm{~d}$ (see Table A-6 in Appendix D). A relatively high Al content in the ITZ at a 
later curing age (28 d) was also reported in previous research [31], where the $\mathrm{Si} / \mathrm{Al}$ ratio in the ITZ was found to be around 1.51 which is lower than that in the paste matrix (i.e. 2.39). Here, the low $\mathrm{Al}$ content in the ITZ at early ages $(<7 \mathrm{~d})$ indicates that the reaction products with low $\mathrm{Al}$ are generated, while Al-rich reaction products are expected to be formed in the ITZ at later curing ages, e.g. $28 \mathrm{~d}$.

To further investigate the reaction process in ITZ, the development of different types of reaction products was discussed based on the ternary $\mathrm{CaO}-\mathrm{Al}_{2} \mathrm{O}_{3}-\mathrm{SiO}_{2}$ diagram plotted in Fig. 15, which was normalised by the content of these oxides by neglecting any other constituents. The chemistry of ITZ at a very early age $(3 \mathrm{~h} \sim 12 \mathrm{~h})$ mainly lies within the region commonly associated with low $\mathrm{Ca} C$ (N)-A-S-H gels, clustered along with the boundary of the region with high Ca C-(N)-A-S-H gels [53]. Nevertheless, it is difficult to find the pure N-A-S-H gels in the ITZ due to the presence of Ca which would hinder the formation of this product $[\underline{53}, \underline{54}$. As the reaction continues $(24 \mathrm{~h}$ to $7 \mathrm{~d})$, the chemistry of ITZ is mainly within the region assigned with high Ca C-(N)-A-S-H gels. This is mainly because of the further dissolution of $\mathrm{Ca}$ from GGBS. Some data points lie in the region containing $\mathrm{C}$ A-S-H gels [54], suggesting that some of the $\mathrm{Na}$ in $\mathrm{C}-(\mathrm{N})-\mathrm{A}-\mathrm{S}-\mathrm{H}$ gels have been fully replaced by the $\mathrm{Ca}$. With the curing age increases from $7 \mathrm{~d}$ to $28 \mathrm{~d}$, the chemistry of ITZ mainly lies in a stable region of high $\mathrm{Ca}$ C-(N)-A-S-H gels with rich $\mathrm{Si}$ and Al, which is in a good agreement with the release process of $\mathrm{Si}$ and $\mathrm{Al}$ shown in Fig. 14c and 14d. This would contribute to the continuous dissolution of FA and GGBS. Given that the content of FA is much higher than that of slag, the higher amount of $\mathrm{Si}$ and $\mathrm{Al}$ can be supplied for producing the well-densified and thermodynamically stable reaction products with rich $\mathrm{Si}$ and $\mathrm{Al}(\mathrm{C}-(\mathrm{N})-\mathrm{A}-\mathrm{S}-\mathrm{H}$ gels) [55, 56], which might contribute to increasing strength and interfacial binding [23]

\subsubsection{Pore structure evolution in the ITZ}

The pore structure of ITZ is another key feature that would strongly determine the properties in this region, such as mechanical properties and transport properties. Fig. 16 shows the porosity of ITZ and paste matrix at different curing ages. The difference in porosity between ITZ and paste matrix in the AAFS system is not obvious, which is in contrast to that in PC system [ $\underline{6}, \underline{9}]$. At $3 \mathrm{~h}$, the porosity of ITZ $(11.45 \%)$ is higher than that of paste matrix $(10.20 \%)$ due to the initial packing of fly ash and slag grains and the presence of bond cracks at the interface between aggregate and paste (see Fig. 9a). The ANOVA test result also indicates that there is a strong significant difference $(p$-value $<0.01)$ of the porosity in the ITZ and paste matrix at $3 \mathrm{~h}$ (see Table A-7 in Appendix D). Afterwards, there is a sharp decrease in porosity with the increase of curing age due to the redistribution of reaction products. At $12 \mathrm{~h}$, the porosity of ITZ and paste matrix is decreased significantly to $2.22 \%$ and $2.45 \%$, respectively. This is the result of the vigorous reaction during the very early age between $3 \mathrm{~h}$ and 12 $\mathrm{h}$, where the space-filling products, i.e. C-(N)-A-S-H gels, are formed in this region, instead of the 
distinct large crystallites, i.e. calcium hydroxide $(\mathrm{CH})$, formed in the $\mathrm{PC}$ system. $\mathrm{CH}$ crystallites are commonly formed close to the aggregate surface in the PC system, which would lead to a relatively high porosity in ITZ [2] . Afterwards, the porosities of ITZ and paste matrix are increased slightly from $2.22 \%$ to $2.45 \%$ and from $2.45 \%$ to $2.74 \%$ respectively during the curing age increasing from $12 \mathrm{~h}$ to $24 \mathrm{~h}$, which can be attributed to the presence of matrix cracks (see Fig. 9c). As the curing continues from $24 \mathrm{~h}$ to $7 \mathrm{~d}$, the porosities of ITZ and paste matrix are decreased steadily from $2.45 \%$ to $1.05 \%$ and from $2.74 \%$ to $0.96 \%$, respectively. This can be ascribed to the continue chemical reaction which would generate the space-filling products (i.e. C-(N)-A-S-H gels) to modify the microstructure and lead to the continuous refinement of pores as well as the improvement of interfacial bonding between aggregate and paste. During these curing ages, the bond cracks and the matrix cracks become finer, and these cracks are almost disappeared at $7 \mathrm{~d}$ (see Fig. 9e). Finally, the porosity of ITZ increases slightly from $1.05 \%$ to $1.35 \%$ as the curing age increases from $7 \mathrm{~d}$ to $28 \mathrm{~d}$, while the porosity of paste matrix increases from $0.96 \%$ to $1.40 \%$. This is probably because of the reappearance of matrix cracks, as shown in Fig. $9 \mathrm{f}$.

To further understand the pore structure evolution, the size distribution of pores in ITZ and paste matrix was analysed. As shown in Fig. 17, the typical images in each sample were used to illustrate the distribution of pore size. The pore size was measured as the circle-equivalent diameter using Fiji (an open source image processing package) with the "Analyze Particles" function [57], in which a cluster of interconnected pores was regarded as a single pore for calculation [49]. A similar trend regarding pore size distribution for ITZ and paste matrix in different images can be recognized (see Appendix C). As seen in Fig. 17a, most pores in the ITZ are larger than those in paste matrix at $3 \mathrm{~h}$ (1 17 $\mu \mathrm{m}$ for ITZ and $0.5 \sim 17.5 \mu \mathrm{m}$ for paste matrix), which can be attributed to the deficit of large grains in the ITZ due to the packing of FA and GGBS particles against aggregates. This would induce a relatively high AL/P ratio in ITZ and lead to the presence of larger pores. A sharp decrease in the size of pores in ITZ and paste matrix $(0.25 \sim 6.75 \mu \mathrm{m}$ for ITZ and $0.3 \sim 4.1 \mu \mathrm{m}$ for paste matrix $)$ can be found at $12 \mathrm{~h}$ (see Fig. 17b), which can be ascribed to the quick alkaline activation of FA and GGBS. This finding is consistent with the EDS analysis shown in Fig. 14. In this stage, although similar small pores $(0.25 \sim 4.1 \mu \mathrm{m})$ can be found in ITZ and paste matrix, the large pores with size from $4.1 \mu \mathrm{m}$ to $6.75 \mu \mathrm{m}$ only exist in the ITZ, which can be attributed to the fewer precursors remaining in the ITZ and thus the newly formed reaction products are not enough to fill the large pores in this region. Nevertheless, as the curing age increases from $24 \mathrm{~h}$ to $7 \mathrm{~d}$, the distribution of pore size in the ITZ is found to be similar to that in the paste matrix due to the redistribution of reaction products (see Fig. $17 \mathrm{c} \sim 17 \mathrm{e}$ ). As the reaction proceeds at $28 \mathrm{~d}$, the pore size in ITZ becomes smaller than that in paste matrix (see Fig. 17f) due to the further redistribution of reaction products through the migration of ions from the dissolution of particles outside the ITZ, which can also be observed from the EDS 
analysis shown in Fig. 14. As seen in Fig. $17 \mathrm{~g}$ and 17h, the pore size in ITZ is decreased steadily with the increase of curing age, while the pore size development in paste matrix is not obvious after $12 \mathrm{~h}$ due to the presence of large fly ash and slag grains in paste matrix. This suggests that ITZ might not be the weak link providing a preferred pathway for aggressive species to pass through the AAFS materials.

\subsection{Mechanism of ITZ evolution}

The formation of ITZ in AAFS concrete is started from the so-called "wall effect", where the FA and GGBS grains are disrupted when they pack through the flat surface of aggregate. This effect would induce the formation of a special region close to aggregate (i.e. the origin of ITZ), where the large grains are deficient in this region (see Fig. 10), leading to a higher effective AL/P ratio than that in paste matrix.

Initially, the precursors in the ITZ and paste matrix are dissolved upon the alkaline activation, generating a variety of dissolved species such as $\mathrm{Si}, \mathrm{Al}$ and $\mathrm{Ca}$. As the quantity of precursors in ITZ is lower than that in paste matrix, the content of dissolved species in ITZ would be lower than that in paste matrix, especially in the initial stage. This explains why the content of $\mathrm{Ca}, \mathrm{Si}$ and $\mathrm{Al}$ in ITZ is lower than that in paste matrix at $3 \mathrm{~h}$ (near final setting time), confirmed by the EDS atomic percentage shown in Fig. 14.

As the reaction continues, much more species are dissolved from precursors and reacted together to form low Ca C-(N)-A-S-H gels at the very early ages from $3 \mathrm{~h}$ to $12 \mathrm{~h}$ (see Fig. 15). In this stage, the dissolved rate in the ITZ is higher than that in the paste matrix due to the higher effective AL/P ratio and the smaller precursor grains in this region. This is consistent with the higher dissolution of $\mathrm{Si}$ and $\mathrm{Al}$ in the ITZ at $12 \mathrm{~h}$, as shown in Fig. 14. The relatively high dissolution rate would help accelerate the formation of reaction products (see Fig. 12) and reduce the porosity (see Fig. 16). Additionally, it would also modify the pore structure in ITZ, where the pore size in ITZ at $12 \mathrm{~h}$ is smaller than that at $3 \mathrm{~h}$ (see Fig. 17).

As a result of the further reaction, the content of dissolved species in ITZ increases steadily along with the formation of high Ca C-(N)-A-S-H gels and C-A-S-H gels due to the release of more Ca from slag, during the curing ages between $12 \mathrm{~h}$ and $7 \mathrm{~d}$ (see Fig. 14 and 15). Consequently, the porosity and pore size are decreased steadily in these curing ages (see Figs. 16 and 17).

Finally, at a later age, the amount of dissolved species in ITZ is increased significantly and becomes higher than that in paste matrix (see Fig. 14). Given that the quantity of initial particle of fly ash and slag in ITZ is lower than that in paste matrix, some species (e.g. Si and Al) might come from the dissolution of precursors in paste matrix rather than ITZ. The relatively high amount of dissolved species would contribute to generating more reaction products (see Fig. 12), refining the pore structure (see Fig. 17) and consequently bringing a more compact and mature microstructure in the 
ITZ. This is similar to the ITZ formed in AAS or AAF concrete [20, 22], but it is different from the ITZ formed in PC concrete [2]. Normally, the ITZ in PC concrete is regarded as the "weak link" due to the higher proportions of pores and $\mathrm{CH}$ crystals in this region $[\underline{8}, \underline{9}$. Nevertheless, there is no distinct large crystallites ( $\mathrm{CH}$ crystals) formed in the ITZ of AAFS concrete but rather the C-(N)-AS-H gels which would improve the strength and interfacial binding [23], which is potentially important for the long-term performance of concrete.

According to the discussion above, the microstructure evolution of ITZ can be primarily divided into three stages: (i) formation of reaction products via quick alkaline activation at very early curing ages $(<12 \mathrm{~h}$ ); (ii) modification of microstructure via the redistribution of reaction products at early curing ages (12 h 7 d); (iii) reorganisation of microstructure via further redistribution of reaction products at later curing ages ( $7 \mathrm{~d} \sim 28 \mathrm{~d})$.

\section{Conclusions}

In this study, the microstructure evolution of interfacial transition zone (ITZ) in alkali-activated fly ash-slag (AAFS) concrete is systematically investigated with the assistance of scanning electron microscope (SEM) equipped with backscattered electron (BSE) and energy dispersive X-ray spectrometer (EDS). Based on the experimental results, the main conclusions can be drawn as follows:

- The ITZ in AAFS system originates from the so-called "wall effect", where the packing of FA and GGBS grains would be disrupted through the flat surface of aggregate, leading to the deficit of large grains adjacent to aggregate and a higher effective AL/P ratio in the ITZ than that in the paste matrix.

- At a very early curing age $(<12 \mathrm{~h})$, a quicker alkaline activation process can be found in the ITZ due to the higher effective AL/P ratio and smaller precursor grains in this region, resulting in a significant increase in the quantity of reaction products (low Ca C-(N)-A-S-H gels) and a sharp reduction in porosity.

- At an early curing age $(12 \mathrm{~h} \sim 7 \mathrm{~d})$, the content of dissolved species in the ITZ increases steadily along with the formation of high $\mathrm{Ca} C-(\mathrm{N})-\mathrm{A}-\mathrm{S}-\mathrm{H}$ gels and $\mathrm{C}-\mathrm{A}-\mathrm{S}-\mathrm{H}$ gels due to the release of more $\mathrm{Ca}$, leading to the continuous refinement of pores in this region.

- At a later curing age ( $7 \mathrm{~d} \sim 28 \mathrm{~d}$ ), the amount of dissolved species in the ITZ increases significantly along with the formation of more stable C-(N)-A-S-H gels with rich Si and Al resulting from the diffusion of species from paste matrix to ITZ due to the concentration gradient developed. Consequently, a more compact and denser microstructure is formed in the ITZ, which is potentially important for the long-term performance of concrete.

- The microstructure evolution of ITZ can be mainly divided into three stages: (i) formation of reaction products via quick alkaline activation at very early curing ages $(<12 \mathrm{~h}$ ); (ii) modification of microstructure via the redistribution of reaction products at early curing ages ( $12 \mathrm{~h} \sim 7 \mathrm{~d}$ ); (iii) 
reorganisation of microstructure via further redistribution of reaction products at later curing ages (7 d 28d).

\section{Acknowledgements}

The authors gratefully acknowledge the financial support from the Engineering and Physical Sciences Research Council (EPSRC) under Grant Nos. EP/R041504/1 and EP/N509577/1 as well as the Royal Society under Award No. IE150587. The financial support provided by University College London (UCL) and China Scholarship Council (CSC) to the first author is also gratefully acknowledged. The authors would like to thank Dr. Yun Gao, Mr. Weiwei Xu, Mr. Shaofeng Qin, Mr. Weipeng Feng and Mr. Yinchu Wang for their support throughout this research.

\section{References}

[1] J.P. Ollivier, J.C. Maso, B. Bourdette, Interfacial transition zone in concrete, Advanced Cement Based Materials, 2 (1995) 30-38.

[2] K.L. Scrivener, A.K. Crumbie, P. Laugesen, The interfacial transition zone (ITZ) between cement paste and aggregate in concrete, Interface Science, 12 (2004) 411-421.

[3] A. Bentur, M.G. Alexander, R.T. Comm, A review of the work of the RILEM TC 159-ETC: Engineering of the interfacial transition zone in cementitious composites, Materials and Structures, 33 (2000) 82-87.

[4] A. Elsharief, M.D. Cohen, J. Olek, Influence of aggregate size, water cement ratio and age on the microstructure of the interfacial transition zone, Cement and Concrete Research, 33 (2003) 1837 1849.

[5] B.D. Barnes, S. Diamond, W.L. Dolch, Micromorphology of the interfacial zone around aggregates in portland cement mortar, Journal of the American Ceramic Society, 62 (1979) 21-24.

[6] P. Xie, J.J. Beaudoin, R. Brousseau, Effect of aggregate size on transition zone properties at the portland cement paste interface, Cement and Concrete Research, 21 (1991) 999-1005.

[7] K. Wu, H. Shi, L. Xu, G. Ye, G. De Schutter, Microstructural characterization of ITZ in blended cement concretes and its relation to transport properties, Cement and Concrete Research, 79 (2016) 243-256.

[8] J.A. Larbi, J.M.J.M. Bijen, Effects of water-cement ratio, quantity and fineness of sand on the evolution of lime in set portland cement systems, Cement and Concrete Research, 20 (1990) 783-794. [9] A.W. Pope, H.M. Jennings, The influence of mixing on the microstructure of the cement paste/aggregate interfacial zone and on the strength of mortar, Journal of Materials Science, 27 (1992) 6452-6462.

[10] K.L. Scrivener, K.M. Nemati, The percolation of pore space in the cement paste/aggregate interfacial zone of concrete, Cement and Concrete Research, 26 (1996) 35-40.

[11] A. Cwirzen, V. Penttala, Aggregate-cement paste transition zone properties affecting the salt- 
frost damage of high-performance concretes, Cement and Concrete Research, 35 (2005) 671-679.

[12] D.N. Winslow, M.D. Cohen, D.P. Bentz, K.A. Snyder, E.J. Garboczi, Percolation and pore structure in mortars and concrete, Cement and Concrete Research, 24 (1994) 25-37.

[13] H.S. Wong, M. Zobel, N.R. Buenfeld, R.W. Zimmerman, Influence of the interfacial transition zone and microcracking on the diffusivity, permeability and sorptivity of cement-based materials after drying, Magazine of Concrete Research, 61 (2009) 571-589.

[14] J. Zheng, H.S. Wong, N.R. Buenfeld, Assessing the influence of ITZ on the steady-state chloride diffusivity of concrete using a numerical model, Cement and Concrete Research, 39 (2009) 805-813. [15] K.L. Scrivener, A.K. Crumbie, P.L. Pratt, A Stludy of the Interfacial Region Between Cement Paste and Aggregate in Concrete, MRS Proceedings, 114 (1988) 87.

[16] A. Leemann, R. Loser, B. Münch, Influence of cement type on ITZ porosity and chloride resistance of self-compacting concrete, Cement and Concrete Composites, 32 (2010) 116-120.

[17] A. Leemann, B. Münch, P. Gasser, L. Holzer, Influence of compaction on the interfacial transition zone and the permeability of concrete, Cement and Concrete Research, 36 (2006) 1425-1433.

[18] M. Zhang, O.E. Gjørv, Microstructure of the interfacial zone between lightweight aggregate and cement paste, Cement and Concrete Research, 20 (1990) 610-618.

[19] D.P. Bentz, Influence of internal curing using lightweight aggregates on interfacial transition zone percolation and chloride ingress in mortars, Cement and Concrete Composites, 31 (2009) 285289.

[20] T. Ji, Q.L. Gao, W.Y. Zheng, X.J. Lin, H.C. Wu, Interfacial transition zone of alkali-activated slag concrete, ACI Materials Journal, 114 (2017) 347-354.

[21] A.R. Brough, A. Atkinson, Automated identification of the aggregate-paste interfacial transition zone in mortars of silica sand with Portland or alkali-activated slag cement paste, Cement and Concrete Research, 30 (2000) 849-854.

[22] W.K.W. Lee, J.S.J. van Deventer, The interface between natural siliceous aggregates and geopolymers, Cement and Concrete Research, 34 (2004) 195-206.

[23] R.S. Nicolas, J.L. Provis, The interfacial transition zone in alkali-activated slag mortars, Front Mater, 2 (2015).

[24] R. San Nicolas, S.A. Bernal, R. Mejía de Gutiérrez, J.S.J. van Deventer, J.L. Provis, Distinctive microstructural features of aged sodium silicate-activated slag concretes, Cement and Concrete Research, 65 (2014) 41-51.

[25] M.A. Smith, G.J. Osborne, Slag/fly ash cements, World Cement Technology, 8 (1977) 223-224.

[26] F. Puertas, S. Martínez-Ramírez, S. Alonso, T. Vázquez, Alkali-activated fly ash/slag cements: Strength behaviour and hydration products, Cement and Concrete Research, 30 (2000) 1625-1632.

[27] N.K. Lee, H.K. Lee, Reactivity and reaction products of alkali-activated, fly ash/slag paste, 
Construction and Building Materials, 81 (2015) 303-312.

[28] J.L. Provis, J.S.J. van Deventer, Alkali activated materials: State-of-the-art report, RILEM TC 224-AAM, Springe, Netherlands, 2014.

[29] G. Fang, W. Ho, W. Tu, M. Zhang, Workability and mechanical properties of alkali-activated fly ash-slag concrete cured at ambient temperature, Construction and Building Materials, 172 (2018) 476-487.

[30] G. Fang, H. Bahrami, M. Zhang, Mechanisms of autogenous shrinkage of alkali-activated fly ash-slag pastes cured at ambient temperature within $24 \mathrm{~h}$, Construction and Building Materials, 171 (2018) 377-387.

[31] B. Singh, M.R. Rahman, R. Paswan, S.K. Bhattacharyya, Effect of activator concentration on the strength, ITZ and drying shrinkage of fly ash/slag geopolymer concrete, Construction and Building Materials, 118 (2016) 171-179.

[32] J.G. Jang, N.K. Lee, H.K. Lee, Fresh and hardened properties of alkali-activated fly ash/slag pastes with superplasticizers, Construction and Building Materials, 50 (2014) 169-176.

[33] A. Keulen, Q. Yu, S. Zhang, S. Grunewald, Effect of admixture on the pore structure refinement and enhanced performance of alkali-activated fly ash-slag concrete, Construction and Building Materials, 162 (2018) 27-36.

[34] BS EN 196-1:2016, Methods of testing cement Part 1: Determination of strength, BSI, 2016.

[35] P. Nath, P.K. Sarker, Effect of GGBFS on setting, workability and early strength properties of fly ash geopolymer concrete cured in ambient condition, Construction and Building Materials, 66 (2014) 163-171.

[36] N.K. Lee, H.K. Lee, Setting and mechanical properties of alkali-activated fly ash/slag concrete manufactured at room temperature, Construction and Building Materials, 47 (2013) 1201-1209.

[37] G. Mallikarjuna Rao, T.D. Gunneswara Rao, A quantitative method of approach in designing the mix proportions of fly ash and GGBS-based geopolymer concrete, Australian Journal of Civil Engineering, 16 (2018) 53-63.

[38] M. Talha Junaid, O. Kayali, A. Khennane, J. Black, A mix design procedure for low calcium alkali activated fly ash-based concretes, Construction and Building Materials, 79 (2015) 301-310.

[39] BS EN 197-1:2011, Cement part 1: Composition, specifications and conformity criteria for common cements, BSI Standards Publication, 2011.

[40] ACI M318-05, Building Code Requirements for Structural Concrete and Commentary, American Concrete Institude, 2005.

[41] S.H. Kosmatka, B. Kerkhoff, W.C. Panarese, Design and Control of Concrete Mixtures, Portland Cement Association, Skokie, Illinois, 2002.

[42] J. Zhang, G.W. Scherer, Comparison of methods for arresting hydration of cement, Cement and 
Concrete Research, 41 (2011) 1024-1036.

[43] K.O. Kjellsen, A. Monsøy, K. Isachsen, R.J. Detwiler, Preparation of flat-polished specimens for SEM-backscattered electron imaging and X-ray microanalysis-importance of epoxy impregnation, Cement and Concrete Research, 33 (2003) 611-616.

[44] H.S. Wong, M.K. Head, N.R. Buenfeld, Pore segmentation of cement-based materials from backscattered electron images, Cement and Concrete Research, 36 (2006) 1083-1090.

[45] Y. Gao, G. De Schutter, G. Ye, H. Huang, Z. Tan, K. Wu, Porosity characterization of ITZ in cementitious composites: Concentric expansion and overflow criterion, Construction and Building Materials, 38 (2013) 1051-1057.

[46] H.S. Wong, N.R. Buenfeld, Patch microstructure in cement-based materials: Fact or artefact?, Cement and Concrete Research, 36 (2006) 990-997.

[47] S. Diamond, M.E. Leeman, Pore Size Distributions in Hardened Cement Paste by Sem Image Analysis, MRS Proceedings, 370 (2011) 217.

[48] M. Nedeljkovic, B. Savija, Y.B. Zuo, M. Lukovic, G. Ye, Effect of natural carbonation on the pore structure and elastic modulus of the alkali-activated fly ash and slag pastes, Construction and Building Materials, 161 (2018) 687-704.

[49] M.H.N. Yio, H.S. Wong, N.R. Buenfeld, 3D pore structure and mass transport properties of blended cementitious materials, Cement and Concrete Research, 117 (2019) 23-37.

[50] V. Bewick, L. Cheek, J. Ball, Statistics review 9: One-way analysis of variance, Critical Care, 8 (2004) 130.

[51] N.J. Salkind, Encyclopedia of Measurement and Statistics, SAGE Publications, Thousand Oaks, California, 2007.

[52] S. Diamond, Considerations in image analysis as applied to investigations of the ITZ in concrete, Cement and Concrete Composites, 23 (2001) 171-178.

[53] J.S.J. van Deventer, R. San Nicolas, I. Ismail, S.A. Bernal, D.G. Brice, J.L. Provis, Microstructure and durability of alkali-activated materials as key parameters for standardization, Journal of Sustainable Cement-Based Materials, 4 (2015) 116-128.

[54] I. Garcia-Lodeiro, A. Palomo, A. Fernández-Jiménez, D.E. Macphee, Compatibility studies between N-A-S-H and C-A-S-H gels. Study in the ternary diagram $\mathrm{Na}_{2} \mathrm{O}-\mathrm{CaO}-\mathrm{Al}_{2} \mathrm{O}_{3}-\mathrm{SiO}_{2}-\mathrm{H}_{2} \mathrm{O}$, Cement and Concrete Research, 41 (2011) 923-931.

[55] R.J. Myers, S.A. Bernal, J.L. Provis, A thermodynamic model for C-(N-)A-S-H gel: CNASH_ss. Derivation and validation, Cement and Concrete Research, 66 (2014) 27-47.

[56] I. Ismail, S.A. Bernal, J.L. Provis, R. San Nicolas, S. Hamdan, J.S.J. van Deventer, Modification of phase evolution in alkali-activated blast furnace slag by the incorporation of fly ash, Cement and Concrete Composites, 45 (2014) 125-135. 
[57] J. Schindelin, I. Arganda-Carreras, E. Frise, V. Kaynig, M. Longair, T. Pietzsch, S. Preibisch, C. Rueden, S. Saalfeld, B. Schmid, J.-Y. Tinevez, D.J. White, V. Hartenstein, K. Eliceiri, P. Tomancak, A. Cardona, Fiji: an open-source platform for biological-image analysis, Nature Methods, 9 (2012) 676-682. 


\section{Figures}



Fig. 1. A schematic diagram for the sample casting and cutting

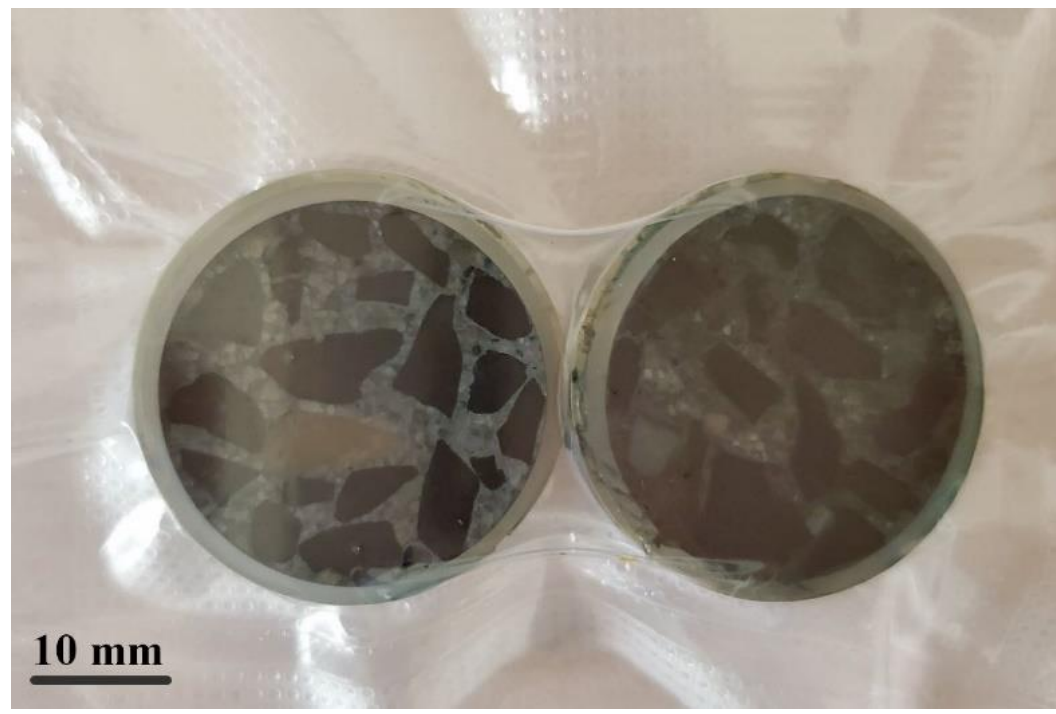

Fig. 2. AAFS concrete samples after grinding and polishing 




Fig. 3. A schematic diagram for the aggregate boundary delineation $(t=24 h)$

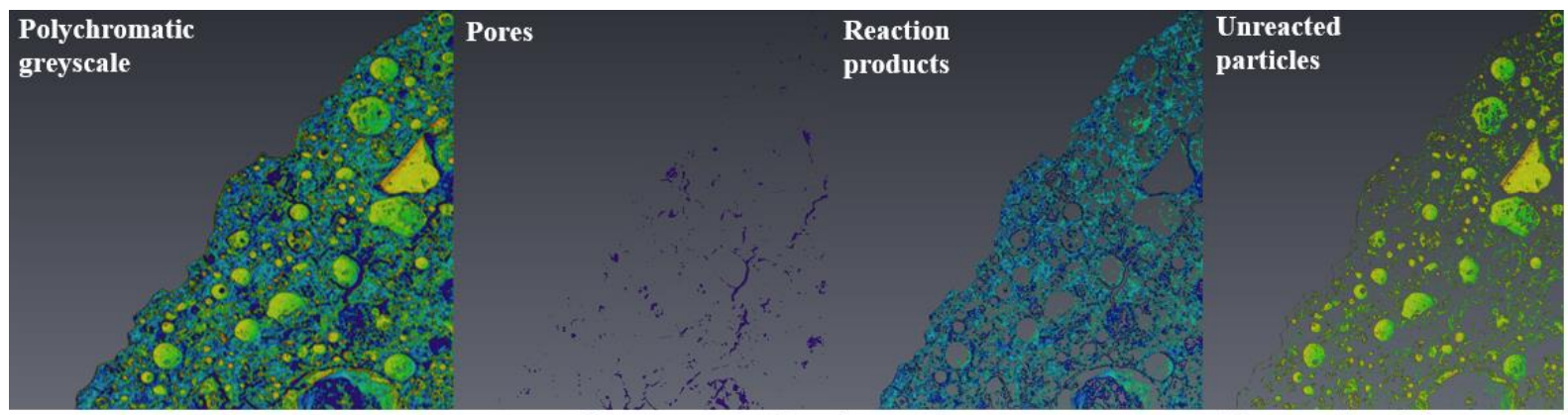

$\underline{50 \mu m}$

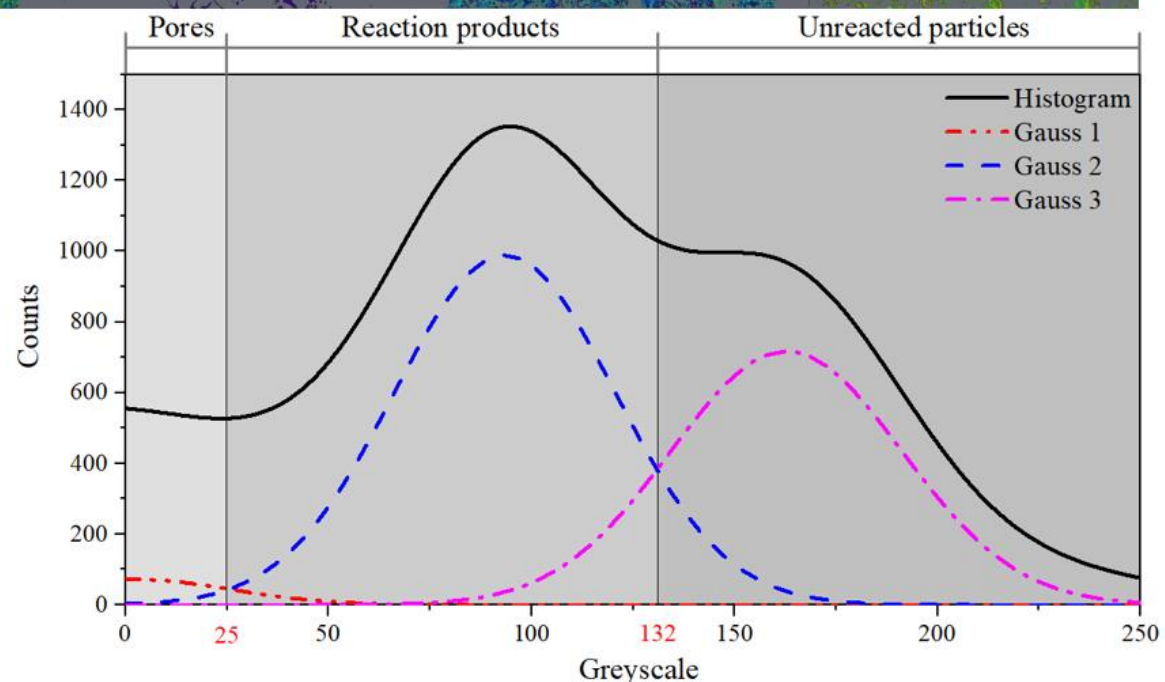

Fig. 4. A typical polychromatic greyscale histogram of different phases in AAFS concrete $(\mathrm{t}=24 \mathrm{~h})$ 
(a)
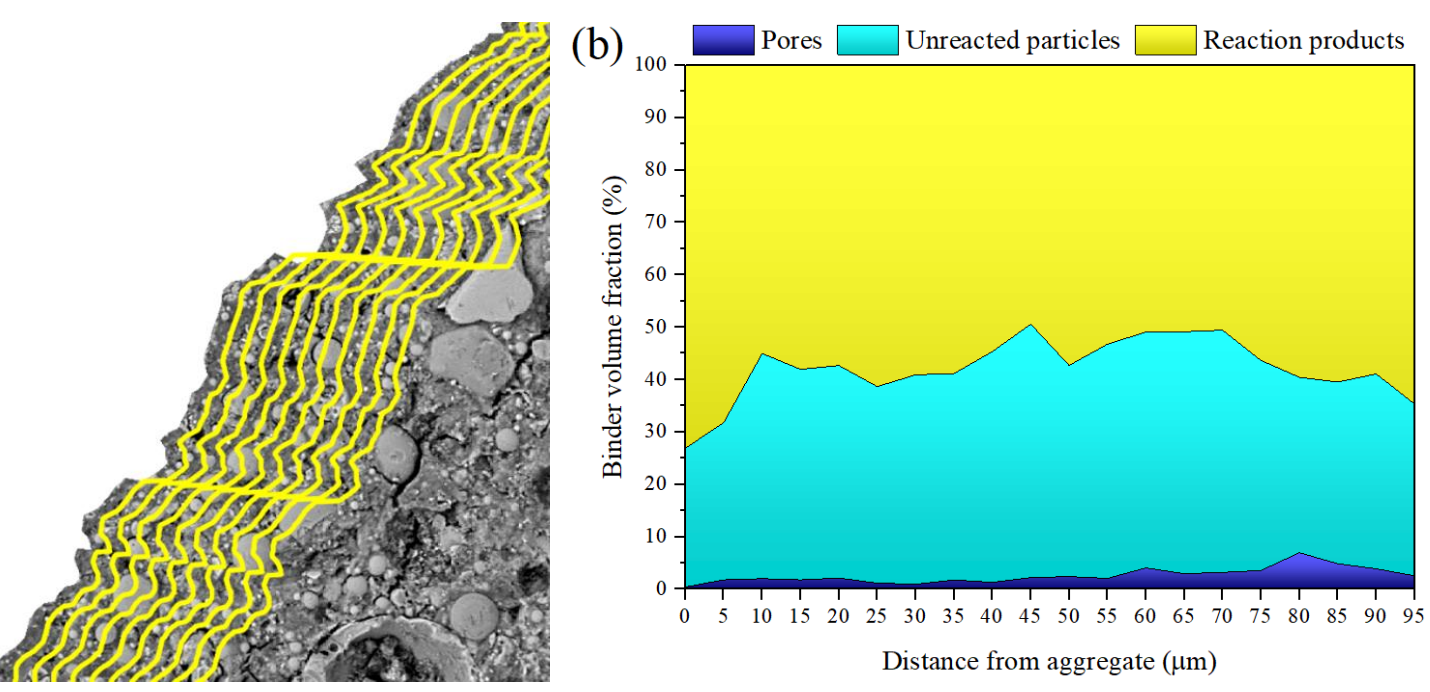

Fig. 5. An example of strip lineation (a) and quantitative analysis using concentric expansion method $(t=24$ h) (b)

(a) 3-h

(b) $12-\mathrm{h}$

(c) $24-\mathrm{h}$

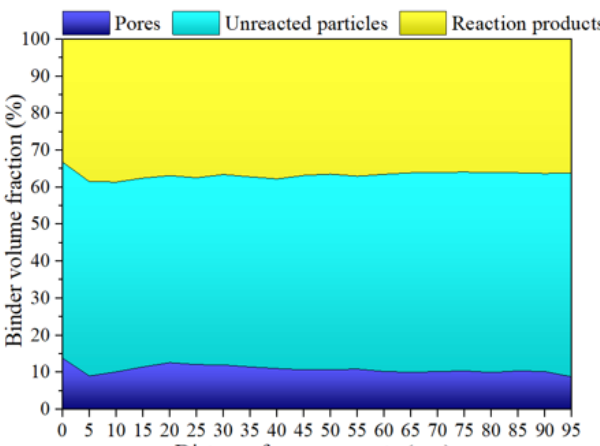

(d) 3-d

Distance from aggregate $(\mu \mathrm{m})$
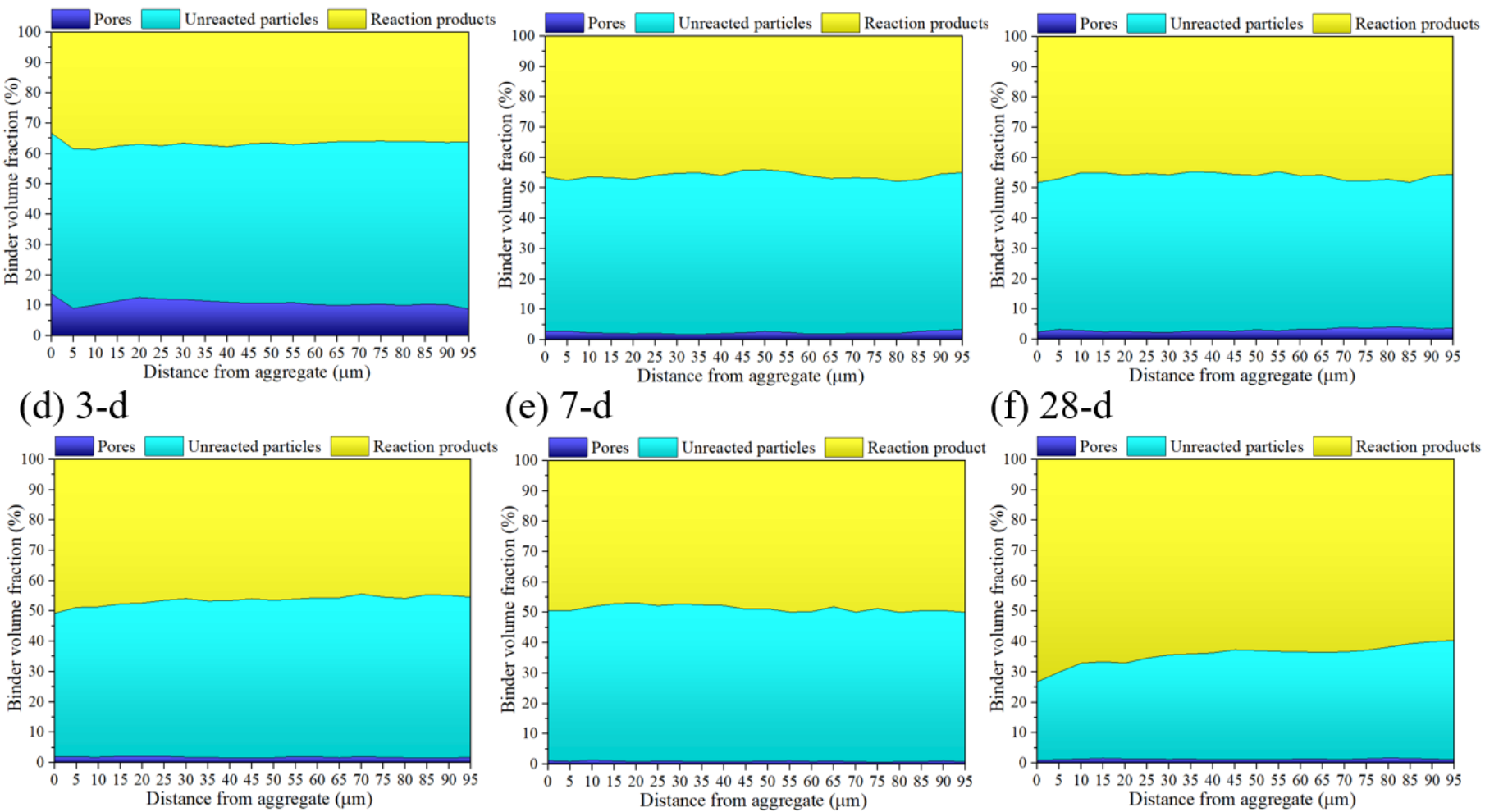

(e) $7-d$

(f) $28-\mathrm{d}$
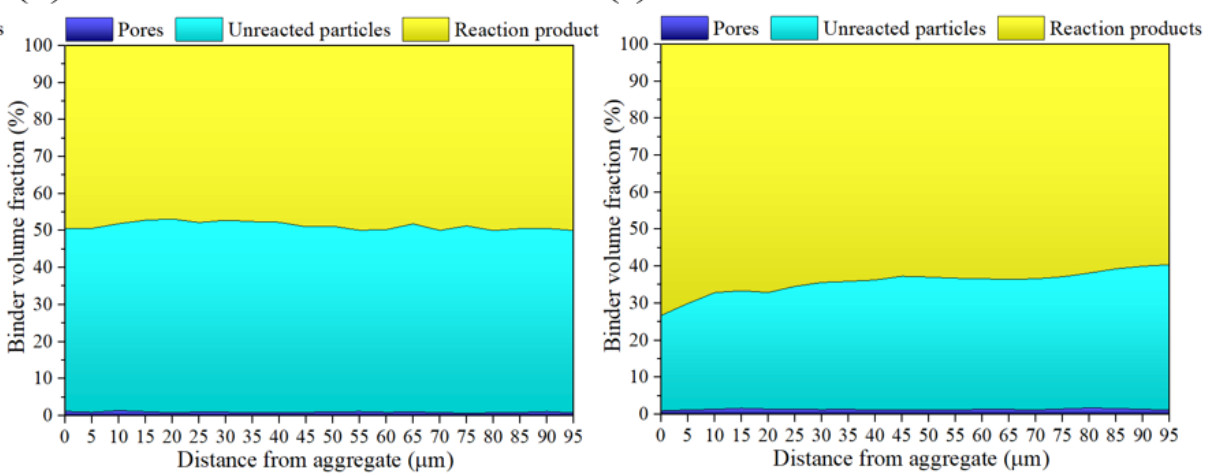

Fig. 6. Volume fractions of different phases against distance from aggregate surface at different curing ages 
(a) $3-\mathrm{h}$

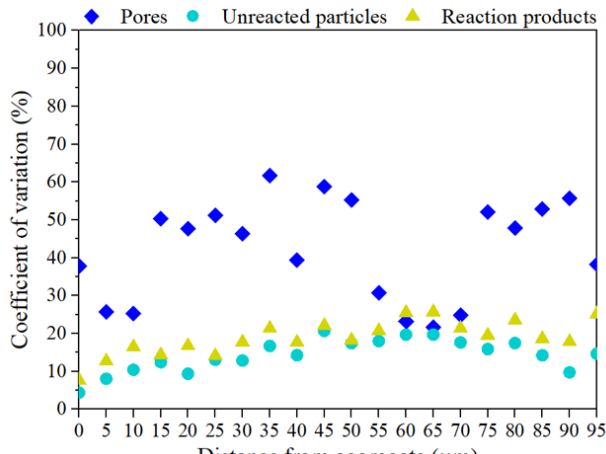

(d) 3-d

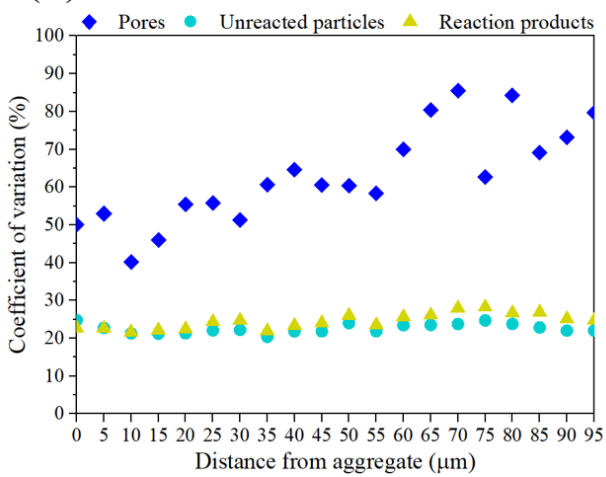

(b) $12-\mathrm{h}$

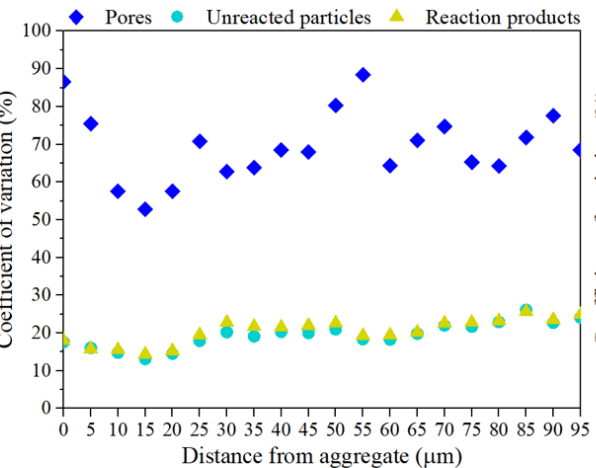

(e) $7-d$

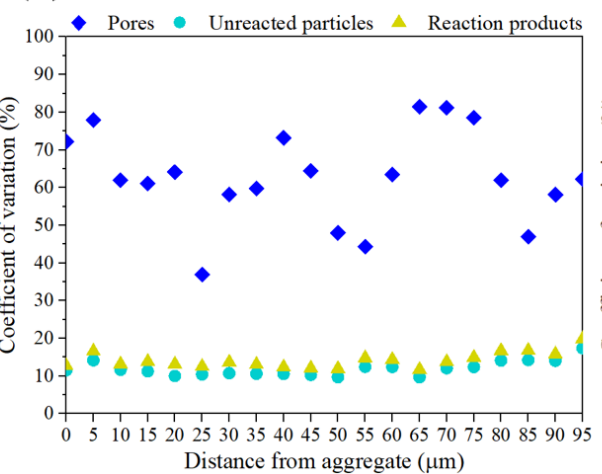

(c) $24-\mathrm{h}$

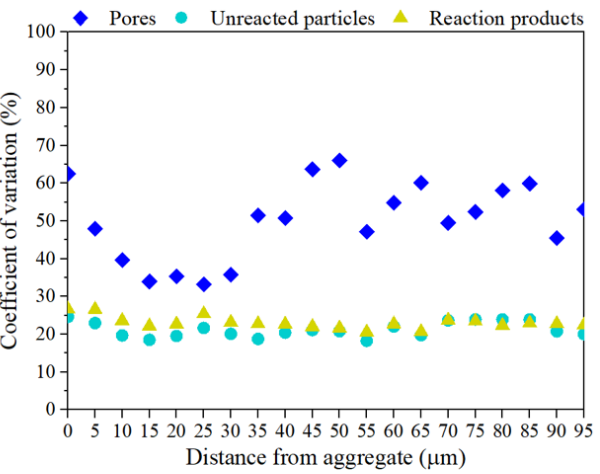

(f) $28-\mathrm{d}$

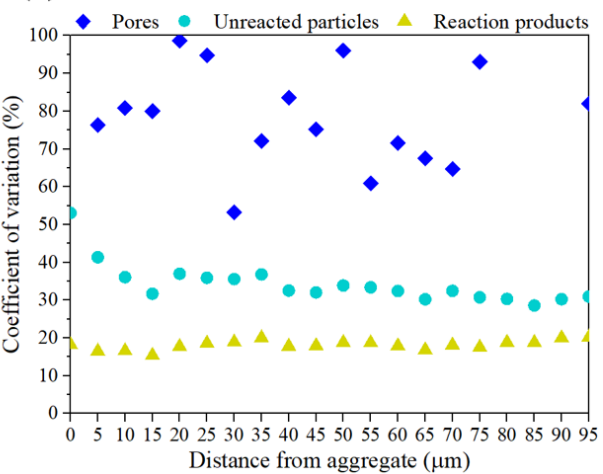

Fig. 7. Coefficients of variation for the volume fractions of different phases against distance from the aggregate surface at different curing ages

(a) 3-h

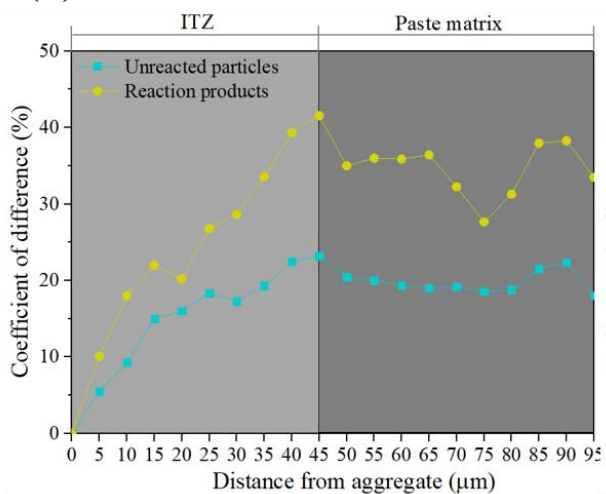

(d) 3-d

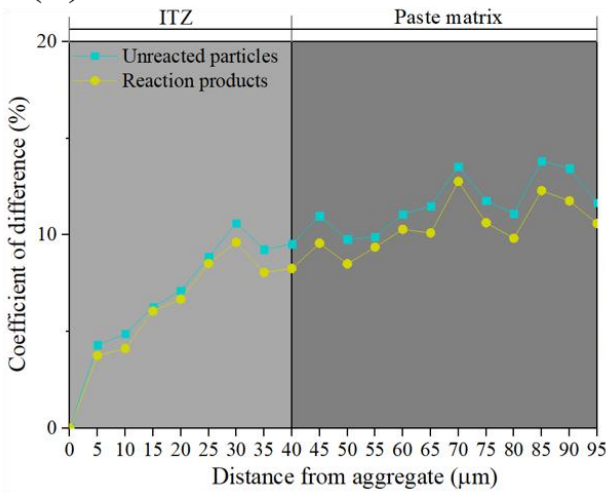

(b) $12-\mathrm{h}$

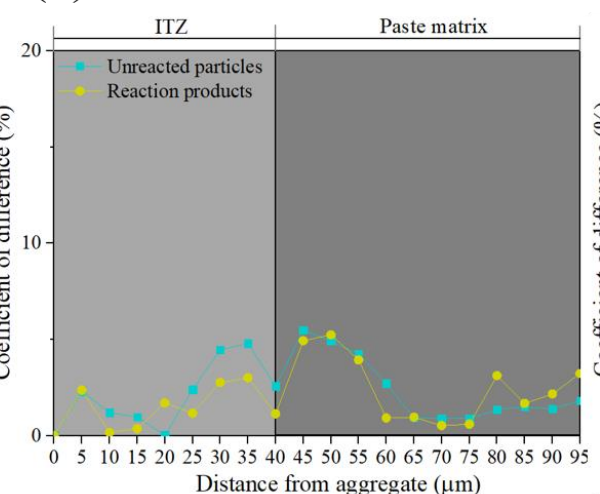

(e) 7 -d

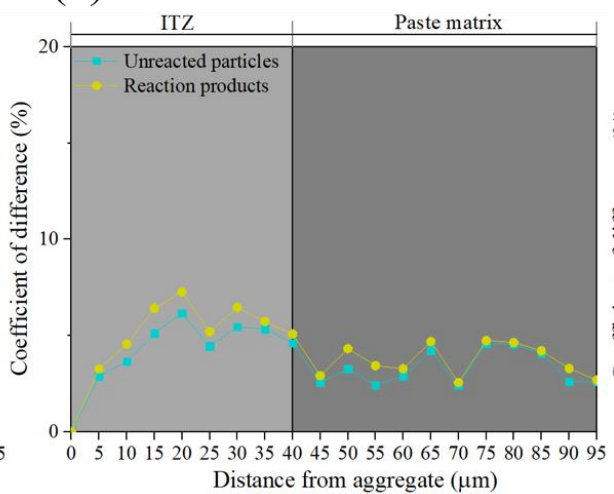

(c) 24-h

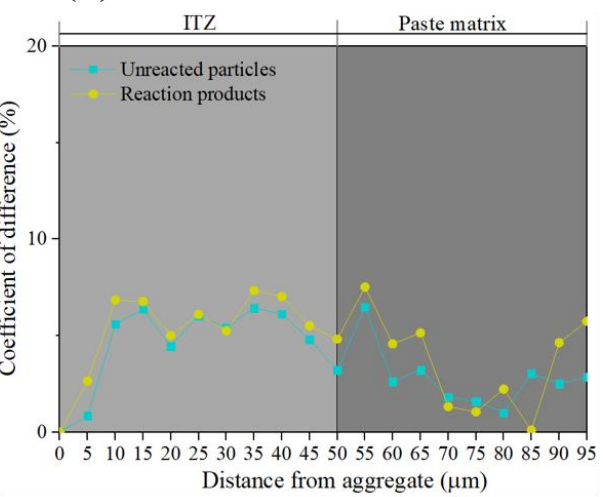

(f) $28-\mathrm{d}$



Fig. 8. Coefficients of difference for the volume fractions of unreacted particles and reaction products against distance from the aggregate surface at different curing ages 
(a) 3-h

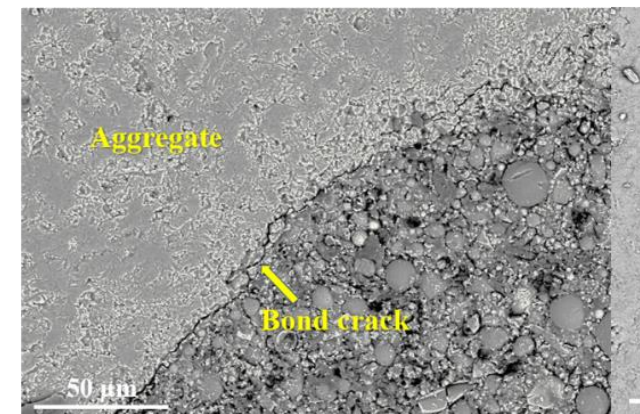

(d) 3-d

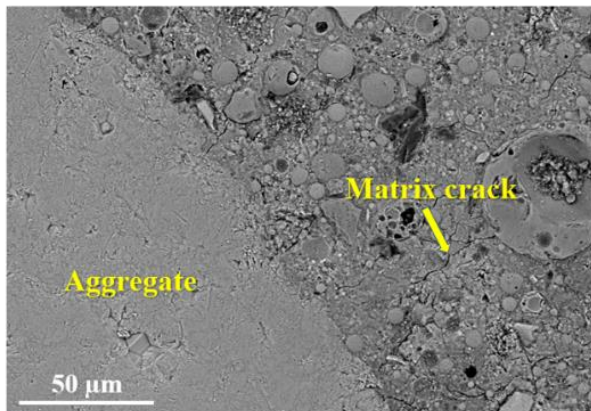

(e) 7-d (c) 24-h

(b) 12-h

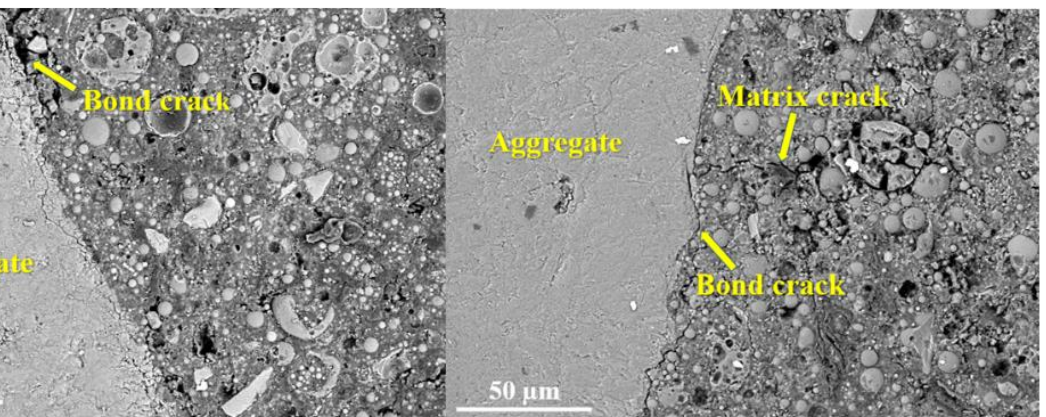

(f) 28-d

Fig. 9. BSEM images of interface between aggregate and paste at different curing ages

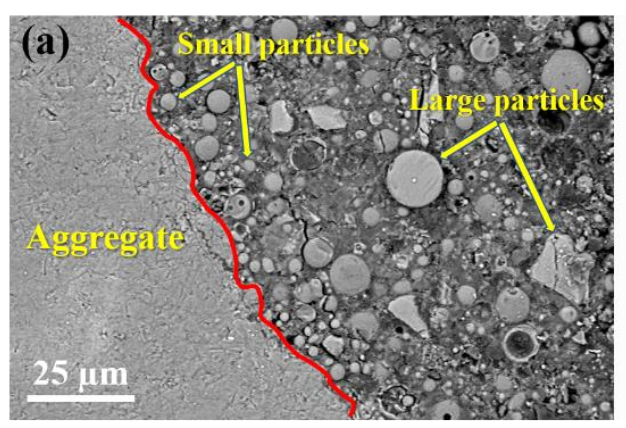

(b)

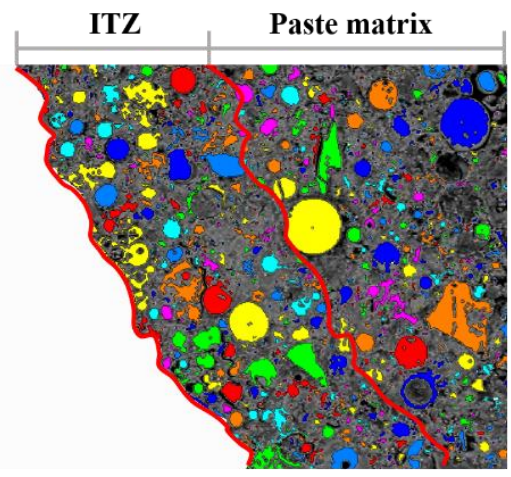



Fig. 10. Particle distribution of fly ash and slag near the surface of aggregate 


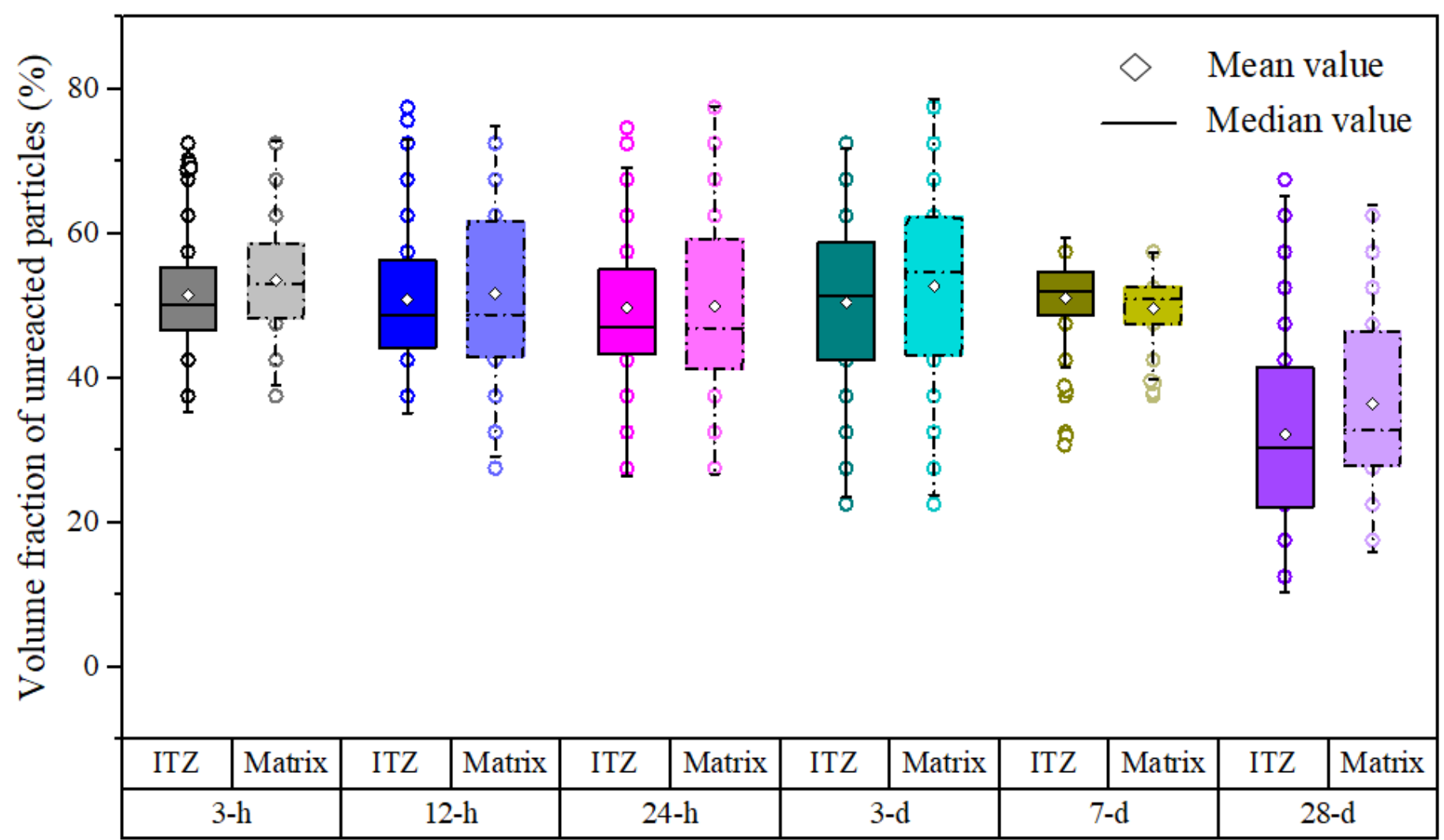

Fig. 11. Volume fractions of unreacted particles in ITZ and paste matrix at different curing ages



Fig. 12. Volume fractions of reaction products in ITZ and paste matrix at different curing ages 
(a) 3-h

Na K $\alpha 1 \_2$

Ca K $\alpha 1$

Si $K \alpha 1$

Al $K \alpha$

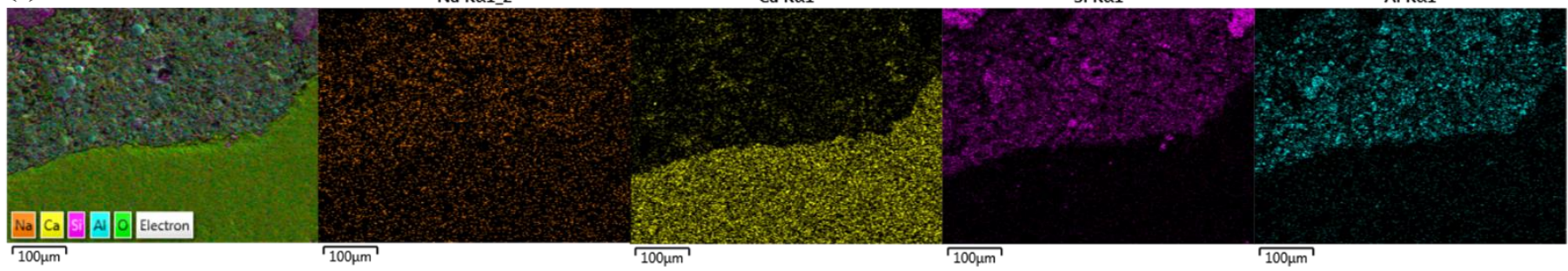

(b) 12-h

Na Ka1_2

$\mathrm{Ca} K \alpha 1$

Si $K \alpha]$

Al $K \alpha$

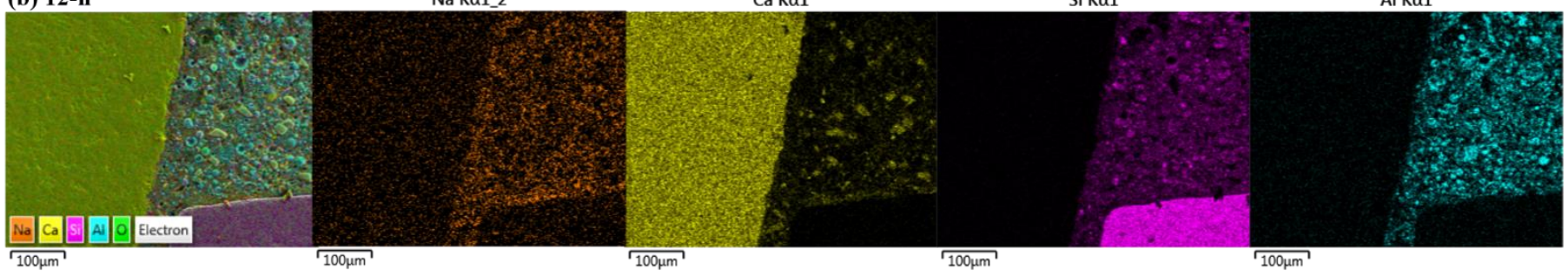

(c) 24-h

Na K $\alpha 1 \_2$

$\mathrm{Ca} K \alpha 1$

Si $K \alpha 1$

Al Ka

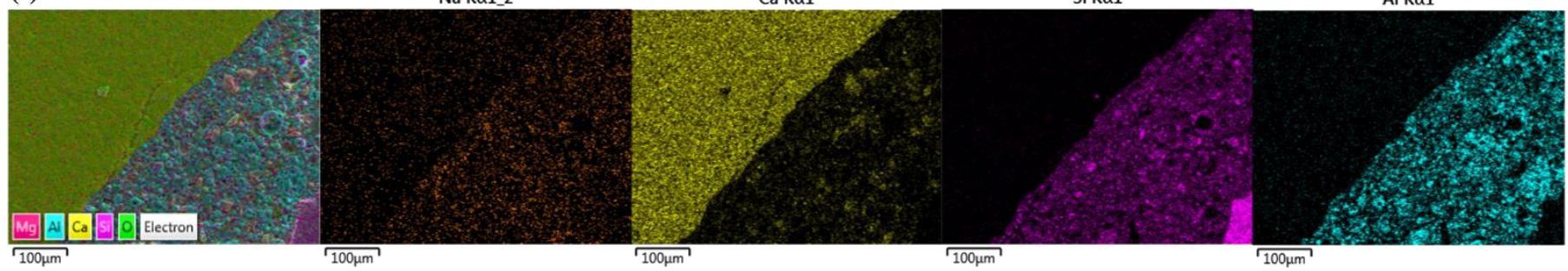

(d) 3-d

Na K $\alpha 1 \_2$

Ca Ka1

Si $K \alpha 1$

Al $K \alpha$

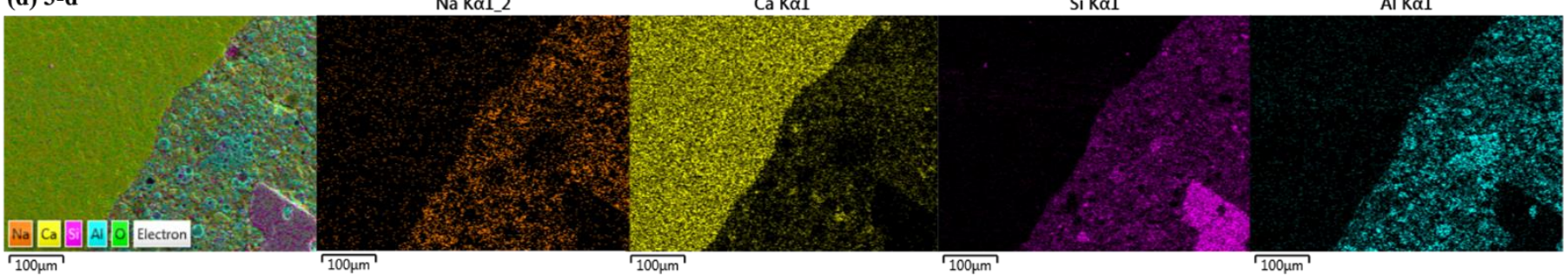

(e) 7-d

Na K $\alpha 1 \_2$

Ca K $\alpha 1$

Si K $\alpha 1$

Al Ka1
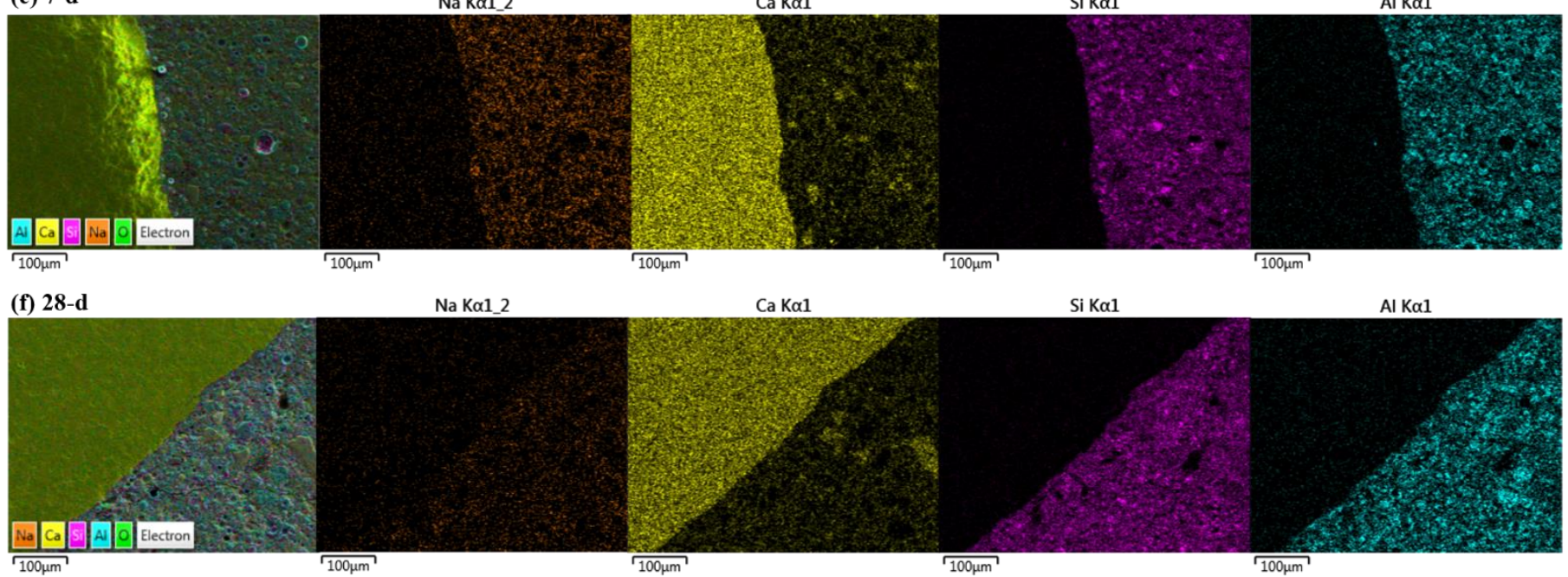

Na K $\alpha 1 \_2$

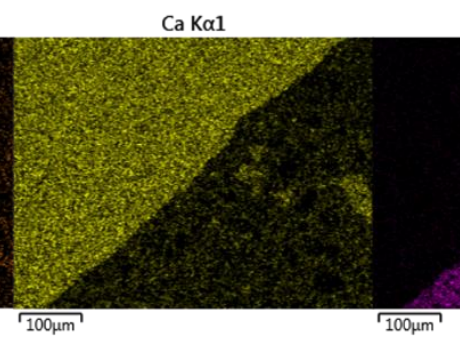

Si K $\alpha 1$

Al $K \alpha]$

Fig. 13. Element maps ( $\mathrm{Na}, \mathrm{Ca}, \mathrm{Si}$ and $\mathrm{Al})$ of the interface between aggregate and paste at different curing ages (based on weight percentages) 
(a)

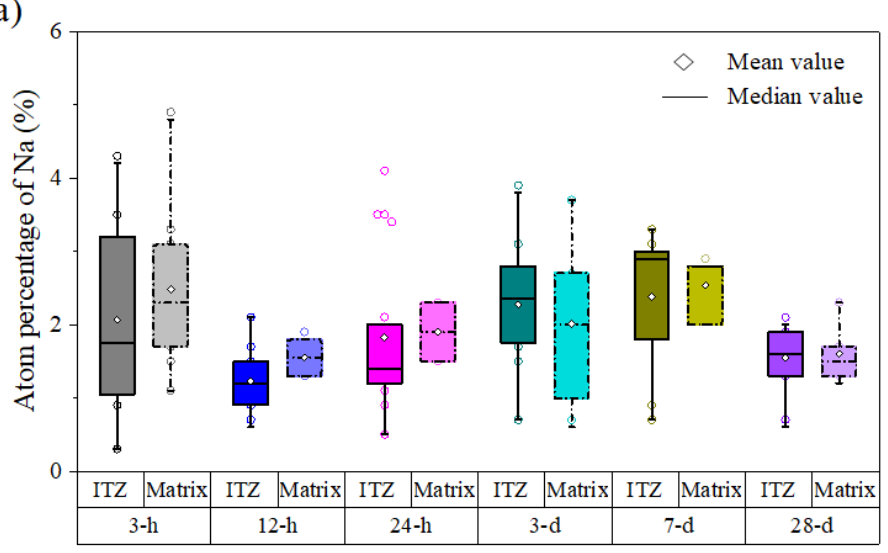

(c)



(b)



(d)

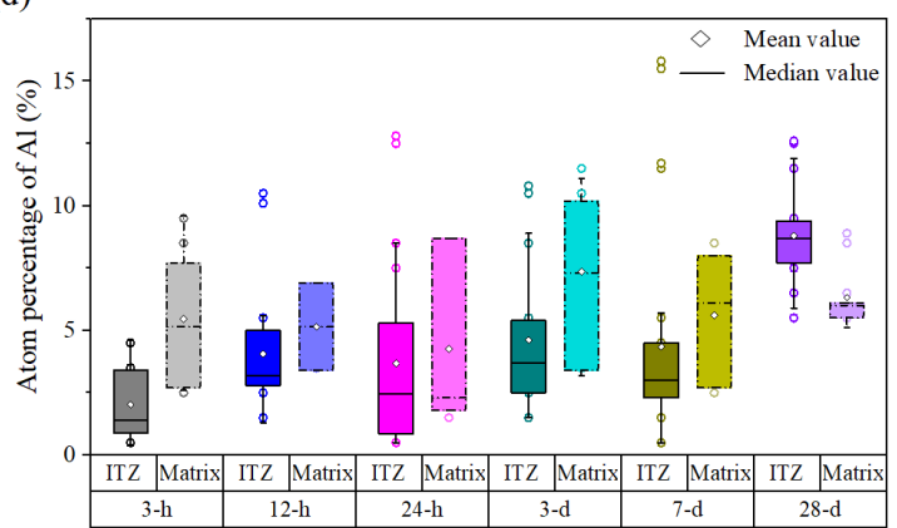

Fig. 14. Atomic percentages ( $\mathrm{Na}, \mathrm{Ca}, \mathrm{Si}$ and $\mathrm{Al})$ in $\mathrm{ITZ}$ and paste matrix at different curing ages

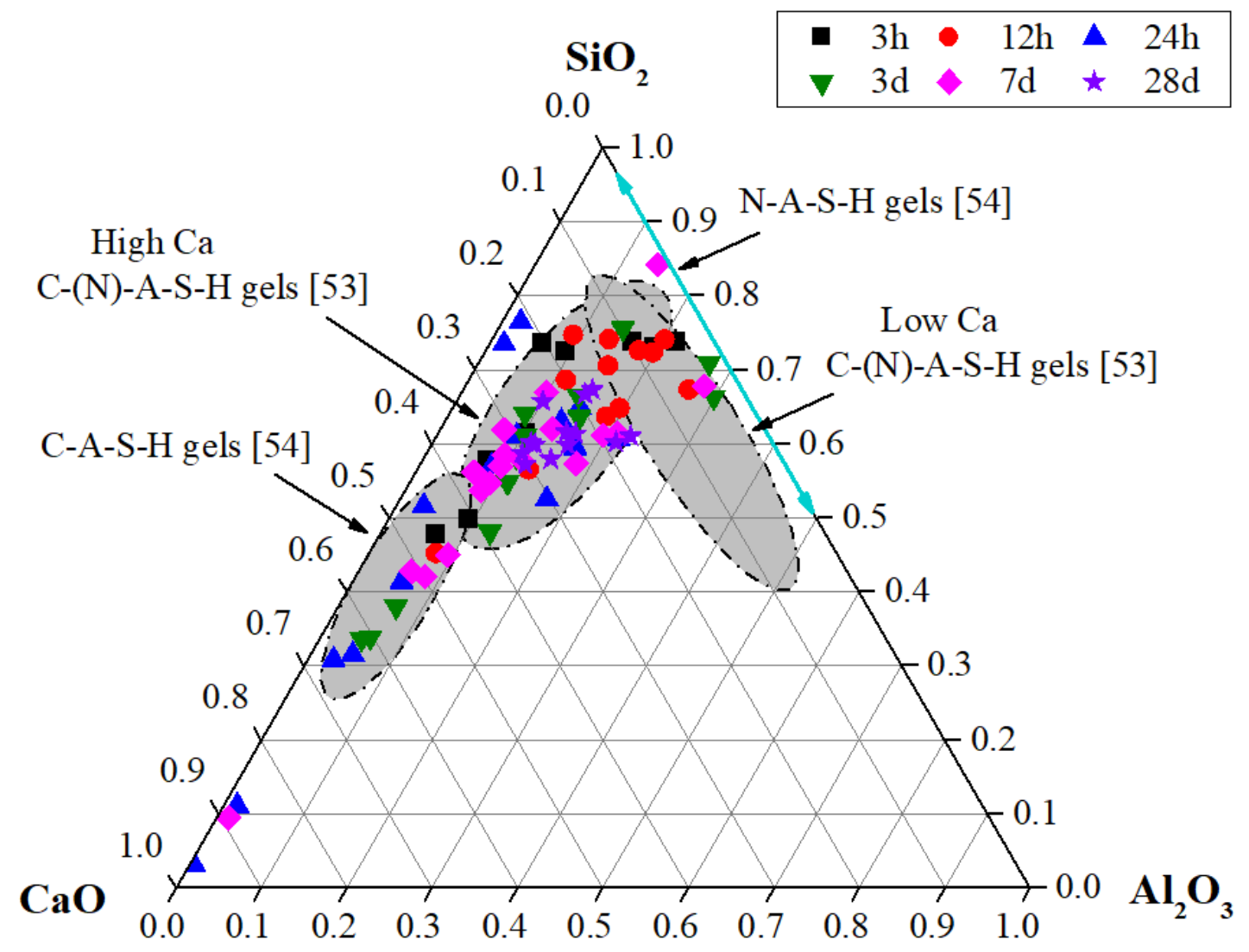

Fig. 15. Ternary $\mathrm{CaO}-\mathrm{Al}_{2} \mathrm{O}_{3}-\mathrm{SiO}_{2}$ diagram of ITZ at different curing ages (based on molar ratios) 


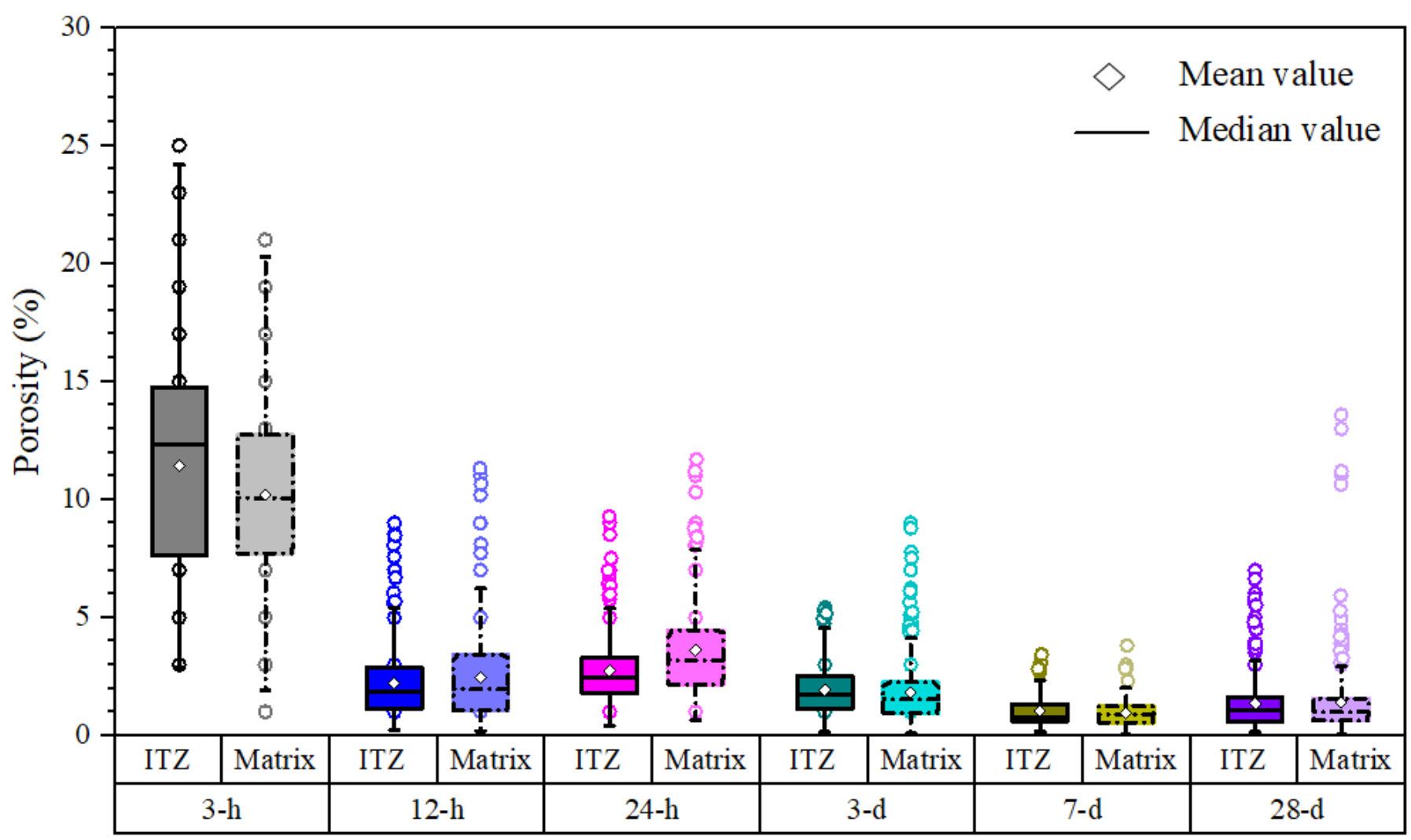

Fig. 16. Porosity of ITZ and paste matrix at different curing ages 
(a) 3-h

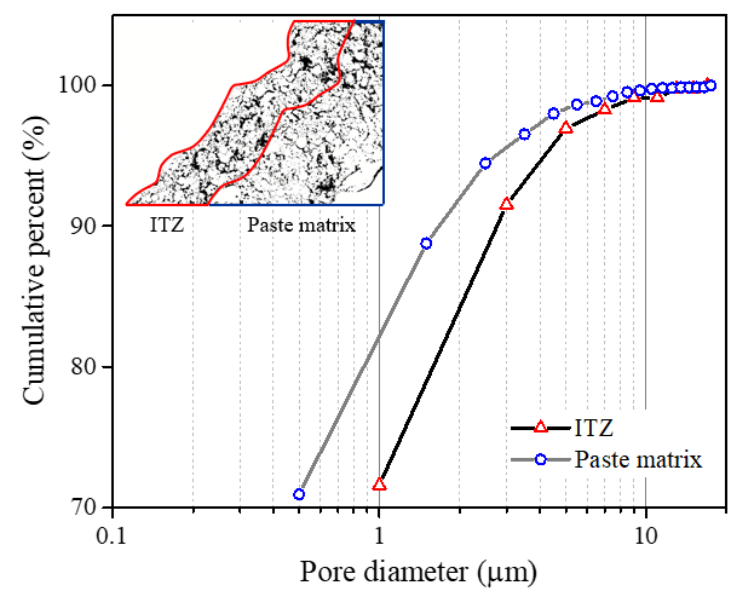

(c) 24-h

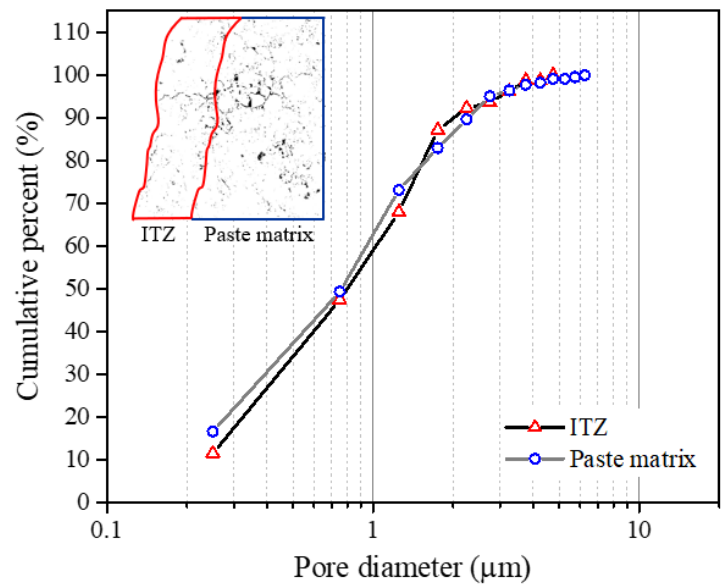

(e) $7-d$

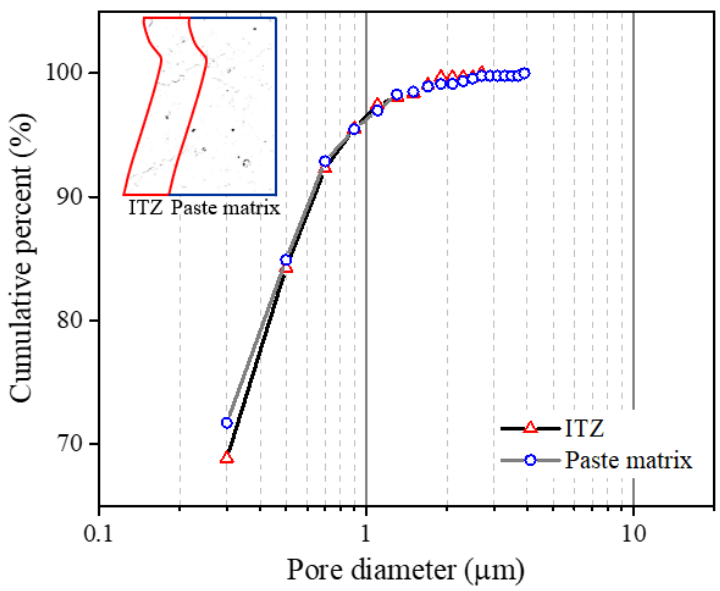

(g) ITZ

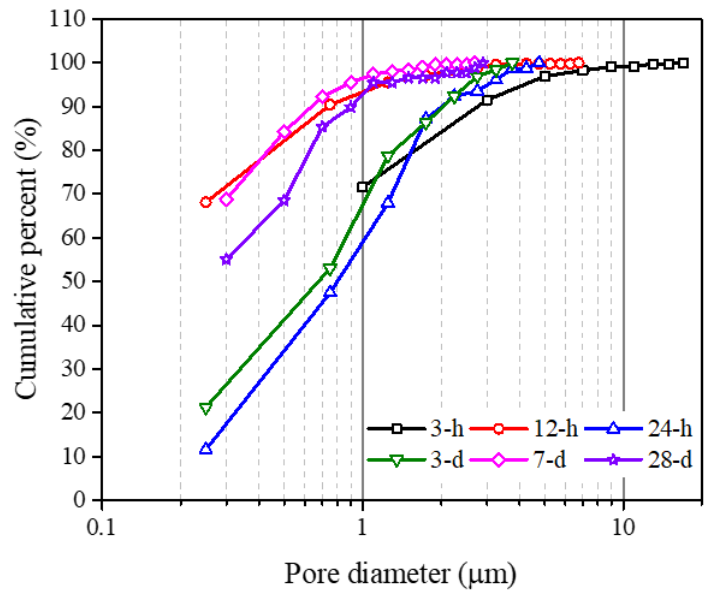

(b) $12-\mathrm{h}$



(d) 3-d



(f) $28-\mathrm{d}$

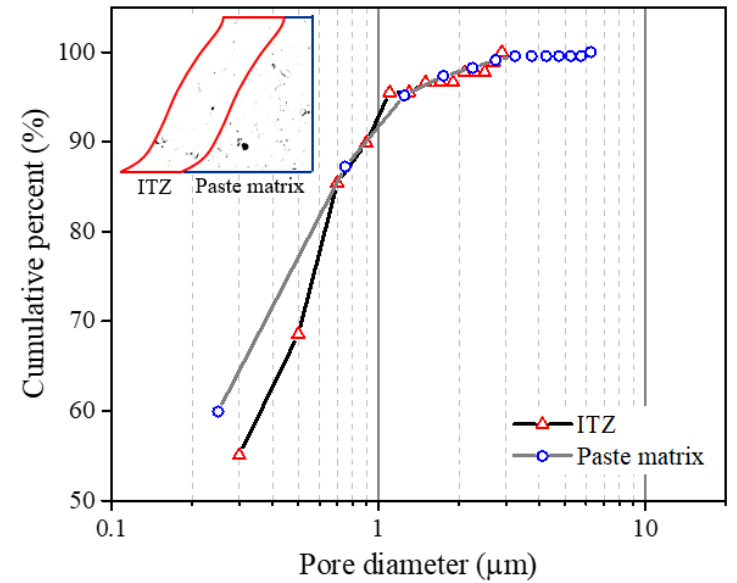

(h) Paste matrix

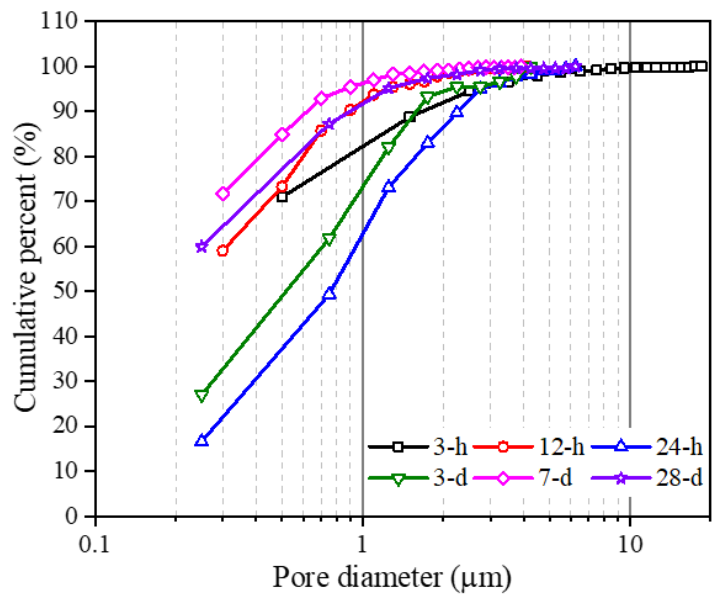

Fig. 17. Pore size distribution in ITZ and paste matrix at different curing ages (Note: a cluster of interconnected pores is classified as a single pore in the characterization of pore structure) 
Tables

Table 1. Chemical composition (wt. \%) of FA and GGBS

\begin{tabular}{ccccccccccc}
\hline Oxide & $\mathrm{SiO}_{2}$ & $\mathrm{Al}_{2} \mathrm{O}_{3}$ & $\mathrm{Fe}_{2} \mathrm{O}_{3}$ & $\mathrm{CaO}$ & $\mathrm{K}_{2} \mathrm{O}$ & $\mathrm{MgO}$ & $\mathrm{TiO}_{2}$ & $\mathrm{Na}_{2} \mathrm{O}$ & $\mathrm{SO}_{3}$ & $\mathrm{P}_{2} \mathrm{O}_{5}$ \\
\hline FA & 55.76 & 30.22 & 3.56 & 2.33 & 0.91 & 0.46 & 1.72 & 0.40 & 0.79 & 0.27 \\
GGBS & 33.22 & 13.49 & 0.40 & 41.57 & 0.64 & 7.04 & 0.50 & 0.34 & 2.14 & - \\
\hline
\end{tabular}

Table 2. Particle size $(\mu \mathrm{m})$ of FA and GGBS

\begin{tabular}{cccccc}
\hline Cumulative distribution & $\mathrm{C}_{1}(10 \%)$ & $\mathrm{C}_{2}(50 \%)$ & $\mathrm{C}_{3}(90 \%)$ & Average particle size & Median particle size \\
\hline FA & 2 & 10 & 32.86 & 19.06 & 11.48 \\
GGBS & 3.08 & 14.50 & 36.07 & 18.98 & 15.78 \\
\hline
\end{tabular}

Table 3. Specific density $\left(\mathrm{g} / \mathrm{cm}^{3}\right)$ of different ingredients in AAFS concrete

\begin{tabular}{cccccccc}
\hline & FA & GGBS & SS & SH & SPs & Fine aggregate & Coase aggregate \\
\hline Specific gravity & 2.25 & 2.90 & 1.38 & 1.21 & 1.08 & 2.57 & 2.62 \\
\hline
\end{tabular}

Table 4. Mixture quantity $\left(\mathrm{kg} / \mathrm{m}^{3}\right)$ of AAFS concrete

\begin{tabular}{cccccccc}
\hline & FA & GGBS & SS & SH & SPs & Fine aggregate & Coase aggregate \\
\hline Mixture quantity & 300 & 100 & 120 & 60 & 4 & 622 & 1178 \\
\hline
\end{tabular}

Table 5. Threshold values for identifying different phases in AAFS concrete

\begin{tabular}{cccc}
\hline Mix no. & Pores & Reaction products & Unreacted particles \\
\hline $3-\mathrm{h}$ & $0 \sim 27$ & $27 \sim 134$ & $134 \sim 255$ \\
$12-\mathrm{h}$ & $0 \sim 27$ & $27 \sim 135$ & $135 \sim 255$ \\
$24-\mathrm{h}$ & $0 \sim 25$ & $25 \sim 132$ & $132 \sim 255$ \\
$3-\mathrm{d}$ & $0 \sim 27$ & $27 \sim 137$ & $137 \sim 255$ \\
$7-\mathrm{d}$ & $0 \sim 27$ & $27 \sim 145$ & $145 \sim 255$ \\
$28-\mathrm{d}$ & $0 \sim 30$ & $30 \sim 140$ & $140 \sim 255$ \\
\hline
\end{tabular}


Appendix A. Phase segmentation for different samples

Additional information about the phase identification for testing samples at different curing ages is shown in Fig. A-1.
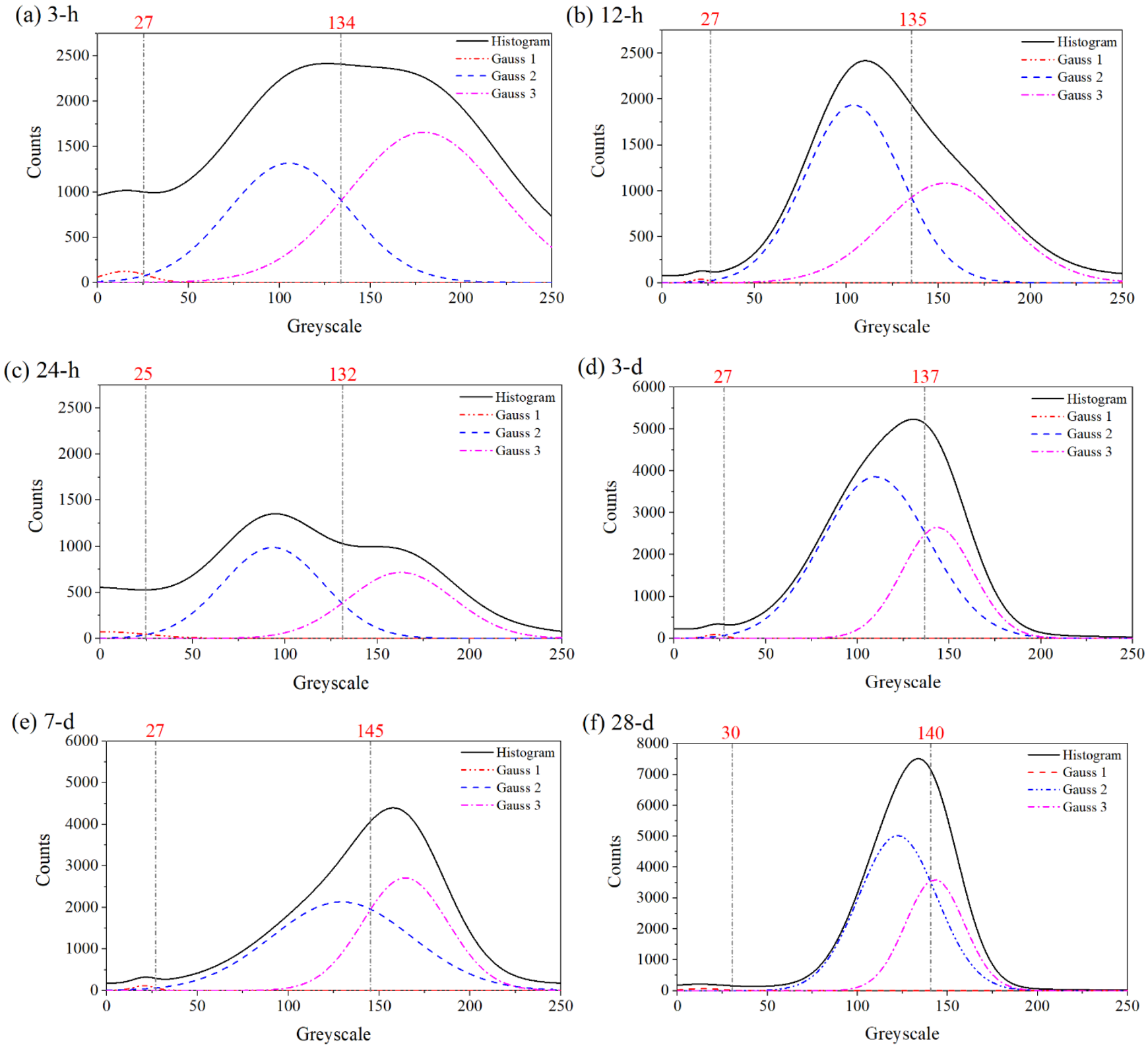

Fig. A-1. Determination of threshold values for testing samples at different curing ages 
Appendix B. Particle size distribution of fly ash and slag in ITZ and paste matrix

As shown in Fig. A-2, the particle size distribution of grains (i.e. fly ash and slag) obtained from two different images for the same sample is slightly different due to the random packing of grains. Nevertheless, the overall trend of particle size distribution in ITZ and paste matrix is similar. The particle size in ITZ is much smaller than that in paste matrix: the size of grains in ITZ and paste matrix ranges from $0.5 \mu \mathrm{m}$ to 11.5 $\mu \mathrm{m}(14.5 \mu \mathrm{m}$ for Image II) and $2.5 \mu \mathrm{m}$ to $62.5 \mu \mathrm{m}$, respectively.

\section{Image I}



Image II

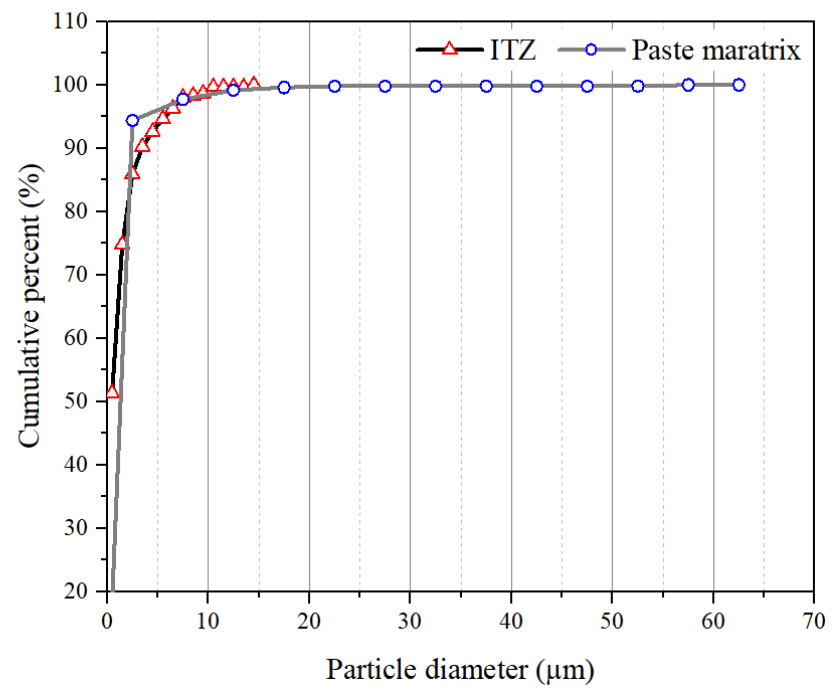

Fig. A-2. Particle size distribution of fly ash and slag obtained from two different images for the same sample 
Appendix C. Pore size distribution in ITZ and paste matrix

A similar trend of pore size distribution in ITZ and paste matrix can be observed in Fig. A-3, indicating that the most pores in ITZ are larger than those in paste matrix. The size of pores in ITZ and paste matrix ranges from $1 \mu \mathrm{m}$ to $17 \mu \mathrm{m}$ and $0.5 \mu \mathrm{m}$ to $17.5 \mu \mathrm{m}$ (16.5 $\mu \mathrm{m}$ for Image II), respectively.

Image I



Image II



Fig. A-3. Pore size distribution in ITZ and paste matrix obtained from two different images for the same sample $(\mathrm{t}=3 \mathrm{~h})$ 
Appendix D. Statistical analysis using the one-way analysis of variance (ANOVA) method

The one-way analysis of variance (ANOVA) tests were performed on the data on volume fractions of different phases (pores, reaction products and unreacted particles), atomic percentages ( $\mathrm{Na}, \mathrm{Ca}, \mathrm{Si}$ and $\mathrm{Al}$ ) and porosity, the results of which are shown in Tables A-1 and A-2, Tables A-3 to A-6, and Table A-7, respectively.

Table A-1 Statistical significance of the volume fractions of unreacted particles

\begin{tabular}{|c|c|c|c|c|}
\hline & & $F$-value & $p$-value & Significance \\
\hline \multirow{2}{*}{$3-h$} & ITZ & \multirow{2}{*}{8.4499} & \multirow{2}{*}{0.0038} & \multirow{2}{*}{$* *$} \\
\hline & Paste matrix & & & \\
\hline \multirow{2}{*}{$12-\mathrm{h}$} & ITZ & \multirow{2}{*}{0.7188} & \multirow{2}{*}{0.3970} & \multirow{2}{*}{-} \\
\hline & Paste matrix & & & \\
\hline \multirow{2}{*}{ 24-h } & ITZ & \multirow{2}{*}{0.0346} & \multirow{2}{*}{0.8526} & \multirow{2}{*}{-} \\
\hline & Paste matrix & & & \\
\hline \multirow{2}{*}{$3-d$} & ITZ & \multirow{2}{*}{5.0210} & \multirow{2}{*}{0.0255} & \multirow{2}{*}{$*$} \\
\hline & Paste matrix & & & \\
\hline \multirow{2}{*}{$7-d$} & ITZ & \multirow{2}{*}{3.8475} & \multirow{2}{*}{0.0512} & \multirow{2}{*}{-} \\
\hline & Paste matrix & & & \\
\hline \multirow{2}{*}{$28-d$} & ITZ & \multirow{2}{*}{16.9626} & \multirow{2}{*}{$0.4558 \times 10^{-4}$} & \multirow{2}{*}{$* *$} \\
\hline & Paste matrix & & & \\
\hline
\end{tabular}

- No significant difference; * Significant difference; ** Strong significant difference.

Table A-2 Statistical significance of the volume fractions of reaction products

\begin{tabular}{|c|c|c|c|c|}
\hline & & $F$-value & $p$-value & Significance \\
\hline \multirow{2}{*}{$3-\mathrm{h}$} & ITZ & \multirow{2}{*}{1.7427} & \multirow{2}{*}{0.1875} & \multirow{2}{*}{-} \\
\hline & Paste matrix & & & \\
\hline \multirow{2}{*}{$12-\mathrm{h}$} & ITZ & \multirow{2}{*}{0.1563} & \multirow{2}{*}{0.6928} & \multirow{2}{*}{-} \\
\hline & Paste matrix & & & \\
\hline \multirow{2}{*}{ 24-h } & ITZ & \multirow{2}{*}{0.5743} & \multirow{2}{*}{0.4490} & \multirow{2}{*}{-} \\
\hline & Paste matrix & & & \\
\hline \multirow{2}{*}{$3-d$} & ITZ & \multirow{2}{*}{4.8685} & \multirow{2}{*}{0.0278} & \multirow{2}{*}{$*$} \\
\hline & Paste matrix & & & \\
\hline \multirow{2}{*}{$7-d$} & ITZ & \multirow{2}{*}{0.3387} & \multirow{2}{*}{0.5610} & \multirow{2}{*}{-} \\
\hline & Paste matrix & & & \\
\hline \multirow{2}{*}{$28-d$} & ITZ & \multirow{2}{*}{14.9629} & \multirow{2}{*}{$1.2553 \times 10^{-4}$} & \multirow{2}{*}{$* *$} \\
\hline & Paste matrix & & & \\
\hline
\end{tabular}

- No significant difference; * Significant difference; ** Strong significant difference. 
Table A-3 Statistical significance of the atomic percentage of $\mathrm{Na}$

\begin{tabular}{|c|c|c|c|c|}
\hline & & $F$-value & $p$-value & Significance \\
\hline $3-\mathrm{h}$ & $\begin{array}{c}\text { ITZ } \\
\text { Paste matrix }\end{array}$ & 0.5348 & 0.4752 & - \\
\hline $12-\mathrm{h}$ & $\begin{array}{c}\text { ITZ } \\
\text { Paste matrix }\end{array}$ & 0.8341 & 0.3826 & - \\
\hline 24-h & $\begin{array}{c}\text { ITZ } \\
\text { Paste matrix }\end{array}$ & 0.0085 & 0.9278 & - \\
\hline $3-d$ & $\begin{array}{c}\text { ITZ } \\
\text { Paste matrix }\end{array}$ & 0.3540 & 0.5597 & - \\
\hline $7-d$ & $\begin{array}{c}\text { ITZ } \\
\text { Paste matrix }\end{array}$ & 0.0747 & 0.7881 & - \\
\hline $28-d$ & $\begin{array}{c}\text { ITZ } \\
\text { Paste matrix }\end{array}$ & 0.0585 & 0.8124 & - \\
\hline
\end{tabular}

- No significant difference.

Table A-4 Statistical significance of the atomic percentage of $\mathrm{Ca}$

\begin{tabular}{|c|c|c|c|c|}
\hline & & $F$-value & $p$-value & Significance \\
\hline \multirow{2}{*}{$3-\mathrm{h}$} & ITZ & \multirow{2}{*}{0.1291} & \multirow{2}{*}{0.7241} & \multirow{2}{*}{-} \\
\hline & Paste matrix & & & \\
\hline \multirow{2}{*}{$12-\mathrm{h}$} & ITZ & \multirow{2}{*}{0.0056} & \multirow{2}{*}{0.9420} & \multirow{2}{*}{-} \\
\hline & Paste matrix & & & \\
\hline \multirow{2}{*}{ 24-h } & ITZ & \multirow{2}{*}{$5.7108 \times 10^{-4}$} & \multirow{2}{*}{0.9813} & \multirow[b]{2}{*}{-} \\
\hline & Paste matrix & & & \\
\hline \multirow{2}{*}{$3-d$} & ITZ & \multirow{2}{*}{1.7122} & \multirow{2}{*}{0.2104} & \multirow{2}{*}{-} \\
\hline & Paste matrix & & & \\
\hline \multirow{2}{*}{$7-d$} & ITZ & \multirow{2}{*}{0.1378} & \multirow{2}{*}{0.7157} & \multirow{2}{*}{-} \\
\hline & Paste matrix & & & \\
\hline \multirow{2}{*}{$28-d$} & ITZ & \multirow{2}{*}{0.0041} & \multirow{2}{*}{0.9502} & \multirow{2}{*}{ - } \\
\hline & Paste matrix & & & \\
\hline
\end{tabular}

- No significant difference.

Table A-5 Statistical significance of the atomic percentage of $\mathrm{Si}$

\begin{tabular}{|c|c|c|c|c|}
\hline & & $F$-value & $p$-value & Significance \\
\hline \multirow{2}{*}{$3-\mathrm{h}$} & ITZ & \multirow{2}{*}{5.6218} & \multirow{2}{*}{0.0316} & \multirow{2}{*}{ * } \\
\hline & Paste matrix & & & \\
\hline \multirow{2}{*}{ 12-h } & ITZ & \multirow{2}{*}{1.3289} & \multirow{2}{*}{0.2758} & \multirow{2}{*}{ - } \\
\hline & Paste matrix & & & \\
\hline \multirow{2}{*}{ 24-h } & ITZ & \multirow{2}{*}{0.0470} & \multirow{2}{*}{0.8318} & \multirow{2}{*}{-} \\
\hline & Paste matrix & & & \\
\hline \multirow{2}{*}{$3-d$} & ITZ & \multirow{2}{*}{0.0530} & \multirow{2}{*}{0.8207} & \multirow{2}{*}{ - } \\
\hline & Paste matrix & & & \\
\hline \multirow{2}{*}{$7-d$} & ITZ & \multirow{2}{*}{0.0162} & \multirow{2}{*}{0.9005} & \multirow{2}{*}{ - } \\
\hline & Paste matrix & & & \\
\hline \multirow{2}{*}{$28-d$} & ITZ & \multirow{2}{*}{0.6095} & \multirow{2}{*}{0.4480} & \multirow{2}{*}{ - } \\
\hline & Paste matrix & & & \\
\hline
\end{tabular}

- No significant difference; * Significant difference. 
Table A-6 Statistical significance of the atomic percentage of Al

\begin{tabular}{|c|c|c|c|c|}
\hline & & $F$-value & $p$-value & Significance \\
\hline \multirow{2}{*}{ 3-h } & ITZ & \multirow{2}{*}{9.1735} & \multirow{2}{*}{0.0085} & \multirow{2}{*}{$* *$} \\
\hline & Paste matrix & & & \\
\hline \multirow{2}{*}{ 12-h } & ITZ & \multirow{2}{*}{0.3230} & \multirow{2}{*}{0.5824} & \multirow{2}{*}{ - } \\
\hline & Paste matrix & & & \\
\hline \multirow{2}{*}{ 24-h } & ITZ & \multirow{2}{*}{0.0567} & \multirow{2}{*}{0.8155} & \multirow{2}{*}{ - } \\
\hline & Paste matrix & & & \\
\hline \multirow{2}{*}{$3-d$} & ITZ & \multirow{2}{*}{3.4518} & \multirow{2}{*}{0.0817} & \multirow[t]{2}{*}{-} \\
\hline & Paste matrix & & & \\
\hline \multirow{2}{*}{$7-d$} & ITZ & \multirow{2}{*}{0.2571} & \multirow{2}{*}{0.6190} & \multirow{2}{*}{ - } \\
\hline & Paste matrix & & & \\
\hline \multirow{2}{*}{$28-d$} & ITZ & \multirow{2}{*}{5.9474} & \multirow{2}{*}{0.0287} & \multirow[t]{2}{*}{$*$} \\
\hline & Paste matrix & & & \\
\hline
\end{tabular}

- No significant difference; $*$ Significant difference; $* *$ Strong significant difference.

Table A-7 Statistical significance of the porosity

\begin{tabular}{|c|c|c|c|c|}
\hline & & $F$-value & $p$-value & Significance \\
\hline \multirow{2}{*}{$3-\mathrm{h}$} & ITZ & \multirow{2}{*}{9.7708} & \multirow{2}{*}{0.0019} & \multirow{2}{*}{$* *$} \\
\hline & Paste matrix & & & \\
\hline \multirow{2}{*}{$12-\mathrm{h}$} & ITZ & \multirow{2}{*}{1.7168} & \multirow{2}{*}{0.1908} & \multirow{2}{*}{-} \\
\hline & Paste matrix & & & \\
\hline \multirow{2}{*}{ 24-h } & ITZ & \multirow{2}{*}{28.5291} & \multirow{2}{*}{$1.4863 \times 10^{-7}$} & \multirow{2}{*}{$* *$} \\
\hline & Paste matrix & & & \\
\hline \multirow{2}{*}{$3-d$} & ITZ & \multirow{2}{*}{0.8043} & \multirow{2}{*}{0.3702} & \multirow{2}{*}{-} \\
\hline & Paste matrix & & & \\
\hline \multirow{2}{*}{$7-d$} & ITZ & \multirow{2}{*}{1.4140} & \multirow{2}{*}{0.2353} & \multirow{2}{*}{ - } \\
\hline & Paste matrix & & & \\
\hline \multirow{2}{*}{$28-d$} & ITZ & \multirow{2}{*}{0.1893} & \multirow{2}{*}{0.6637} & \multirow[t]{2}{*}{ - } \\
\hline & Paste matrix & & & \\
\hline
\end{tabular}

- No significant difference; $* *$ Strong significant difference. 